\title{
Functional Data Analysis of Weather Variables Linked to Fusarium Head Blight Epidemics in the United States
}

\author{
D. A. Shah ${ }^{\dagger}$ E. D. De Wolf, P. A. Paul, and L. V. Madden
}

First and second authors: Department of Plant Pathology, Kansas State University, Manhattan 66506; and third and fourth authors: Department of Plant Pathology, The Ohio State University, Ohio Agricultural Research and Development Center, Wooster 44691. Accepted for publication 11 June 2018.

\begin{abstract}
In past efforts, input weather variables for Fusarium head blight (FHB) prediction models in the United States were identified after following some version of the window-pane algorithm, which discretizes a continuous weather time series into fixed-length windows before searching for summary variables associated with FHB risk. Functional data analysis, on the other hand, reconstructs the assumed continuous process (represented by a series of recorded weather data) by using smoothing functions, and is an alternative way of working with time series data with respect to FHB risk. Our objective was to functionally model weather-based time series data linked to 865 observations of FHB (covering 16 states and 31 years in total), classified as epidemics (FHB disease index $\geq 10 \%$ ) and nonepidemics (FHB disease index $<10 \%$ ). Altogether, 94 different time series variables were modeled by penalized cubic B-splines for the smoothing function, from 120 days pre-anthesis to 20 days post-anthesis. Functional mean curves,

standard deviations, and first derivatives were plotted for FHB epidemics relative to nonepidemics. Function-on-scalar regressions assessed the temporal trends of the magnitude and significance of the mean difference between functionally represented weather time series associated with FHB epidemics and nonepidemics. The mean functional weather-variable curve for epidemics started to deviate, in general, from that for nonepidemics as early as 40 days pre-anthesis for several weather variables. The greatest deviations were often near anthesis, the period of maximum susceptibility of wheat to FHB-causing fungi. The most consistent separations between the mean functional curves were seen with the daily averages of moisturerelated variables (such as average relative humidity) and with variables summarizing the daily variation in temperature (as opposed to the daily mean). Functional data analysis was useful for extending our knowledge of relationships between weather variables and FHB epidemics.
\end{abstract}

Fusarium head blight (FHB) in the United States is caused mainly by Fusarium graminearum sensu stricto (O'Donnell et al. 2000, 2004; Starkey et al. 2007), and is a disease of enduring economic concern across the small grains industry (Nganje et al. 2004). The importance of FHB is reflected by numerous reviews and summaries written within the last 10 years, covering aerobiology (Keller et al. 2014), cultivar resistance (Gilbert and Haber 2013; Prat et al. 2014), epidemiology (Osborne and Stein 2007), fungal genomics (Kazan et al. 2012), host-pathogen interactions at the genomic level (Trail 2009; Walter et al. 2010), legislation (Ferrigo et al. 2016), mycotoxins in grain (Wegulo 2012), and pathogen persistence on crop residue (Leplat et al. 2013). In the United States, FHB is managed at different points of the grain supply chain (Bianchini et al. 2015), beginning with in-field disease mitigation (Cowger et al. 2016; Paul et al. 2008; Willyerd et al. 2012) and harvest strategies (Salgado et al. 2011, 2014).

Field-level FHB management combines moderately resistant cultivars (when possible; most U.S. wheat cultivars are moderately or highly susceptible to FHB) (Jin et al. 2013) with a demethylation inhibitor fungicide applied at flowering or shortly thereafter (D'Angelo et al. 2014; Freije and Wise 2015; Wegulo et al. 2011,

${ }^{\dagger}$ Corresponding author: D. A. Shah; E-mail: dashah81@k-state.edu

Funding: This is a cooperative project with the U.S. Wheat \& Barley Scab Initiative (agreements 59-0206-6-015 [Kansas State University] and 59-0206-4-018 [The Ohio State University]). Salaries and research support for L. V. Madden and P. A. Paul were provided by state and federal funds to the Ohio Agricultural Research and Development Center. Salary and research support for E. D. De Wolf were provided by federal funds to Kansas State University.

*The $\boldsymbol{e}$-Xtra logo stands for "electronic extra" and indicates that two supplementary figures and three supplementary files are published online.

(C) 2019 The American Phytopathological Society
2015; Willyerd et al. 2012). Even so, control of FHB symptoms and deoxynivalenol (DON) mycotoxin content of grain can be less than desired (Paul et al. 2007b, 2008, 2010) and, moreover, is not guaranteed because post-anthesis weather can still push DON levels beyond acceptable limits (Cowger and Arrellano 2010; Del Ponte et al. 2007). Given the sporadic occurrences of FHB epidemics, fungicide applications may not always be cost-effective, depending on larger economic forces, or even necessary, if weather conditions do not favor FHB during anthesis or post-anthesis.

Forecast models predicting the probability of severe FHB epidemics are a useful part of a decision support system (DSS) as growers or managers determine whether a fungicide application is warranted (Gent et al. 2013; Yuen and Mila 2015). FHB forecasting in the United States has focused on the prediction of severe epidemics (FHB disease index $\geq 10 \%$ ), conditional on the predictions being made by anthesis to allow sufficient lead time for fungicide applications to be made, if so desired. The premise is that reduction of FHB leads to an associated reduction in DON, because FHB symptom intensity and DON levels are often positively correlated (Paul et al. 2005; Wegulo 2012). Earlier work by our group showed that U.S. FHB epidemics are correlated with weather close to anthesis (De Wolf et al. 2003; Kriss et al. 2010). Variables summarizing dewpoint depression, rainfall, relative humidity, temperature, and vapor pressure deficit in short pre-anthesis windows (5 to 15 days long) were used to develop novel FHB forecast models (Molineros 2007; Shah et al. 2013, 2014), some of which were incorporated into the web-based DSS for FHB in U.S. wheat (http://www.wheatscab. psu.edu/). Although the web-based DSS is used routinely throughout the eastern and central U.S. wheat-growing areas, stakeholders do want improved prediction accuracy (Giroux et al. 2016; Hollingsworth et al. 2006; Wegulo et al. 2015). In a more general sense, the FHB DSS is under continuous refinement as more data are added, newer predictive algorithms are tested, and more is learned about the epidemiology of FHB and DON. 
When developing a weather-based disease forecasting system, it is crucial to identify variables to be used as predictors. A very common technique used in this regard within plant disease epidemiology is the segmentation of a weather time series into discrete periods (windows), followed by the creation of variables summarizing conditions within the windows and the application of a correlationbased analysis to select the summary variables most associated with the disease in question (Pietravalle et al. 2003; Te Beest et al. 2008, 2009). The formalized window-pane algorithm (Coakley et al. 1988) iteratively searches through overlapping periods within a weather time series with the objective of identifying those summaries (e.g., mean temperature in a 10-day window) correlated with a disease outcome (such as infection or symptom appearance). We used the discrete-time-window paradigm as a guiding principle when creating predictor variables summarizing weather conditions within short time spans relative to anthesis (De Wolf et al. 2003; Kriss et al. 2010; Shah et al. 2013, 2014). The discrete-window approach to variable identification and model building is not without some shortcomings. Models stemming from the discrete-time-window approach typically restrict all input variables to the same fixed-length windows (De Wolf et al. 2003; Moschini and Fortugno 1996; Shah et al. 2013; Xu et al. 2013) or to nonoverlapping periods relative to heading or anthesis (Schaafsma and Hooker 2007). It leads to a high dimensional space of possibly highly correlated variables, which then creates a variable selection problem (Gouache et al. 2015; Shah et al. 2013). Spurious correlations with the outcome are also a concern (Pietravalle et al. 2003). Moreover, the user must define the starting point for windows, the window length, and the amount of overlap among windows. These choices necessarily lead to an arbitrary discretization of a continuous weather time series, and the possibility that a signal in the series will be split among several adjacent or overlapping windows. Essentially, the discretization of a weather time series makes it difficult to identify just how continuous a signal is relative to FHB.

In this article, we approached the relationship between weather and FHB from a functional perspective. The basic idea was to represent an entire weather time series by a mathematical function, which was further analyzed with respect to its relationship to FHB epidemics. Functional data analysis (FDA) is a rapidly growing area of study (Greven and Scheipl 2017), with several recent examples of application in the ecological and environmental fields (Bonner et al. 2014; Gertheiss et al. 2015; Masselot et al. 2016). Readers are referred to Ramsay and Silverman (2005) and Ramsay et al. (2009) at the introductory level, to recent reviews (Morris 2015; Wang et al. 2016) for further topics in FDA, and to Sørensen et al. (2013) for illustrated examples of FDA from the medical field. Readers interested in learning more about functional data analysis are also directed to the Functional Data Analysis Website (http://www. psych.mcgill.ca/misc/fda/index.html).

In this article, we examined the relationship between FHB epidemics and functionally represented weather time series variables. The first objective was to create functional representations of weather time series associated with the two classes of FHB observations (epidemics and nonepidemics), considering a wider time interval than previously examined (Shah et al. 2013, 2014) and new types of weather-based variables. The functional curves for the two classes were compared graphically and via functional summaries. The second objective was to determine whether the mean functional weather curves differed statistically between FHB epidemics and nonepidemics and, if so, at which points along the time series.

\section{MATERIALS AND METHODS}

The observational data matrix. FHB incidence and severity data were collected, as described previously (Shah et al. 2013), from nonfungicide-treated plots established and maintained through projects funded by the U.S. Wheat \& Barley Scab Initiative. For the current article, the earlier data set (Shah et al. 2013) was expanded from 527 to 865 observations (unique combinations of locationyear, cultivar reaction [resistance] to FHB, and flowering date), taken over the years 1982 to 2014 in 16 states (Arkansas, Illinois, Indiana, Kansas, Kentucky, Maryland, Michigan, Minnesota, Missouri, North Dakota, Nebraska, New York, Ohio, Pennsylvania, South Dakota, and Wisconsin). Data included observations made on four FHB resistance classes (very susceptible, susceptible, moderately susceptible, and moderately resistant) on both spring and winter wheat. FHB (severe; major) epidemics (defined as field severity [FHB disease index] $\geq 10 \%$ ) (Shah et al. 2013) made up $27 \%$ of the observations.

The weather data. Our past efforts (De Wolf et al. 2003; Shah et al. 2013, 2014) had relied on collaborators forwarding us weather data associated with their FHB observations. For the current article, we removed that burden from collaborators by directly accessing weather station data via custom-written scripts. For each field plot location, Mathematica's WeatherData function (version 10.4; Wolfram Research, Champaign, IL) was used to identify the closest weather station reporting dewpoint $\left(\mathrm{D} ;{ }^{\circ} \mathrm{C}\right)$, barometric pressure $(\mathrm{P} ; \mathrm{hPa})$, and temperature $\left(\mathrm{T} ;{ }^{\circ} \mathrm{C}\right)$ for the period 60 days post-anthesis going back to 1 September in the year prior (i.e., a period corresponding to planting through harvest for North American wheat). This latter approach was also taken in a recent Belgian FHB study (Landschoot et al. 2013a). The standardization of weather data retrieval led to more efficient postprocessing and error checking. It also allowed access to weather data up to the fall of the year prior to crop maturity; collaborators typically sent measurements for a much shorter time interval ( 52 days pre-anthesis to 50 days post-anthesis, on average). Obtaining weather data this way is not without disadvantages, the primary one being that the measurements were not coincident (spatially) with FHB observation sites; sourced weather stations were, on average, $27 \mathrm{~km}$ (range $=2.1$ to $76.1 \mathrm{~km}$ ) from plot locations; $80 \%$ of stations were within $43 \mathrm{~km}$ of plot sites.

All postacquisition data preparation and analysis was done with R (64-bit version 3.3.2; R Foundation for Statistical Computing, Vienna) on Windows 10 Pro (Microsoft Corp., Redmond, WA). Postacquisition processing included checking for duplicate entries, missing values, out-of-range or implausible values (e.g., D > T), and apparent sensor errors. Erroneous values were set to missing. In all cases, weather data had been recorded at least hourly, sometimes more frequently. Time series were summarized to hourly observations using the openair (version 1.5) package. On average, 4.7, 6.5, and $4.5 \%$ of hourly data values were missing in the $\mathrm{D}, \mathrm{P}$, and $\mathrm{T}$ weather time series, respectively. Cubic spline interpolation (na. spline function in the zoo package [version 1.7-12]) was used to impute missing data gaps up to $12 \mathrm{~h}$ long for D and T and up to $24 \mathrm{~h}$ long for P. Longer gaps were imputed with the mnimput function in the mtsdi package (version 0.3.3). The mnimput function implements a modified version of the expectation-maximization algorithm, which accounts for the correlation structure within and across time series (Junger et al. 2003). A smoothing spline was used at each iteration step. All series were rechecked postimputation for credibility (adherence to the distributional properties of the original series) via summary statistics, plots of the imputed time series, and histograms of the imputed data distributions.

Postimputation, relative humidity (RH; \%), vapor pressure deficit (VPD; $\mathrm{kPa}$ ), and temperature-dewpoint depression (TDD; ${ }^{\circ} \mathrm{C}$ ) were estimated from T and D (Monteith and Unsworth 2008). Saturated vapor pressure $\left(\mathrm{vp}_{\mathrm{s}} ; \mathrm{kPa}\right)$ was calculated from $\mathrm{T}$ by $\mathrm{vp}_{\mathrm{s}}=0.611 \times$ $10^{(7.5 \mathrm{~T}) /(237.3+\mathrm{T})}$. The actual vapor pressure $\left(\mathrm{vp}_{\mathrm{a}} ; \mathrm{kPa}\right)$ was calculated from $\mathrm{D}$ by $\mathrm{vp}_{\mathrm{a}}=0.611 \times 10^{10(7.5 \mathrm{D}) /(237.3+\mathrm{D})}$. Then, $\mathrm{VPD}=\mathrm{vp}_{\mathrm{s}}-$ $\mathrm{vp}_{\mathrm{a}}$ and $\mathrm{RH}=100\left(\mathrm{vp}_{\mathrm{a}} / \mathrm{vp}_{\mathrm{s}}\right)$. TDD is simply $\mathrm{T}-\mathrm{D}$.

The T, D, P, RH, VPD, and TDD hourly time series data were then used to estimate several groups of derived series. The most straightforward groups were daily summaries of a variable, the most elementary being the 24-h mean (average) T (T.A), D (D.A), P (P.A), RH (RH.A), VPD (VPD.A), and TDD (TDD.A). The respective nighttime (2000 to 0800 h) 12-h means were T.AN, D.AN, P.AN, 
RH.AN, VPD.AN, and TDD.AN. Other daily (24-h) summaries were the minimum observed value (T.MIN, D.MIN, P.MIN, RH. MIN, VPD.MIN, and TDD.MIN), the maximum observed value (T.MAX, D.MAX, P.MAX, RH.MAX, VPD.MAX, and TDD.MAX), the difference between the observed maximum and minimum values (T.MINMAXDIFF, D.MINMAXDIFF, P.MINMAXDIFF, RH.MINMAXDIFF, VPD.MINMAXDIFF, and TDD.MINMAXDIFF), the 10th percentile (T.10P, D.10P, P.10P, RH.10P, VPD.10P, and TDD.10P), the 90th percentile (T.90P, D.90P, P.90P, RH.90P, VPD.90P, and TDD.90P), and the difference between the 90th and 10th percentiles (T.PDIFF, D.PDIFF, P.PDIFF, RH.PDIFF, VPD. PDIFF, and TDD.PDIFF). The daily standard deviations of the observed values (T.SD, D.SD, P.SD, RH.SD, VPD.SD, and TDD. SD), and the nighttime standard deviations (T.SDN, D.SDN, P.SDN, RH.SDN, VPD.SDN, and TDD.SDN) were also estimated. Cumulative-type summaries are described in Table 1 . These derived series reflected variables identified by our previous work as being associated with FHB (De Wolf et al. 2003; Shah et al. 2013, 2014), as well as variables considered or suggested by other recent FHB research (percentiles, VPD.L11.CHD, VPD.L635.CHD, VPD.L6. CD, TRH.5T30nRHG75.CHD, and TRH.20T25nRHG85.CHD) (Landschoot et al. 2012; Manstretta and Rossi 2015; Manstretta and Rossi 2016). All series were aligned relative to the respective anthesis dates as the reference point (time $=0$ ). Altogether, $W=94$ weather time series variables were constructed.

TABLE 1. Weather variables used in the functional data analysis

\begin{tabular}{|c|c|}
\hline Group, condition to be met ${ }^{\mathrm{a}}$ & Abbreviation \\
\hline \multicolumn{2}{|l|}{ Cumulative number of hours } \\
\hline $\mathrm{RH} \geq 70 \%$ & RH.G70.CHD \\
\hline $\mathrm{RH} \geq 80 \%$ & RH.G80.CHD \\
\hline $\mathrm{RH} \geq 90 \%$ & RH.G90.CHD \\
\hline $14^{\circ} \mathrm{C}<\mathrm{T}<22^{\circ} \mathrm{C}$ & T.14T22.CHD \\
\hline $15^{\circ} \mathrm{C} \leq \mathrm{T} \leq 30^{\circ} \mathrm{C}$ & T.15T30.CHD \\
\hline $\mathrm{T}>30^{\circ} \mathrm{C}$ & T.G30.CHD \\
\hline $\mathrm{T}<15^{\circ} \mathrm{C}$ & T.L15.CHD \\
\hline $\mathrm{T}<9^{\circ} \mathrm{C}$ & T.L9.CHD \\
\hline $15^{\circ} \mathrm{C} \leq \mathrm{T} \leq 30^{\circ} \mathrm{C}$ and $\mathrm{RH} \geq 80 \%$ & TRH.15T30nRHG80.CHD \\
\hline $15^{\circ} \mathrm{C} \leq \mathrm{T} \leq 30^{\circ} \mathrm{C}$ and $\mathrm{RH} \geq 90 \%$ & TRH.15T30nRHG90.CHD \\
\hline $20^{\circ} \mathrm{C} \leq \mathrm{T} \leq 25^{\circ} \mathrm{C}$ and $\mathrm{RH} \geq 85 \%$ & TRH.20T25nRHG85.CHD \\
\hline $5^{\circ} \mathrm{C} \leq \mathrm{T} \leq 30^{\circ} \mathrm{C}$ and $\mathrm{RH} \geq 75 \%$ & TRH.5T30nRHG75.CHD \\
\hline $9^{\circ} \mathrm{C} \leq \mathrm{T} \leq 30^{\circ} \mathrm{C}$ and $\mathrm{RH} \geq 90 \%$ & TRH.9T30nRHG90.CHD \\
\hline $\mathrm{VPD}<0.1 \mathrm{kPa}$ & VPD.L01.CHD \\
\hline $\mathrm{VPD} \leq 1.1 \mathrm{kPa}$ & VPD.L11.CHD \\
\hline $\mathrm{VPD} \leq 0.635 \mathrm{kPa}$ & VPD.L635.CHD \\
\hline \multicolumn{2}{|l|}{ Cumulative number of nighttime hours } \\
\hline $\mathrm{RH} \geq 70 \%$ & RH.G70.CHN \\
\hline $\mathrm{RH} \geq 80 \%$ & RH.G80.CHN \\
\hline $\mathrm{RH} \geq 90 \%$ & RH.G90.CHN \\
\hline $\mathrm{TDD}<1.0^{\circ} \mathrm{C}$ & TDD.L1.CHN \\
\hline $15^{\circ} \mathrm{C} \leq \mathrm{T} \leq 30^{\circ} \mathrm{C}$ and $\mathrm{RH} \geq 80 \%$ & TRH.15T30nRHG80.CHN \\
\hline $15^{\circ} \mathrm{C} \leq \mathrm{T} \leq 30^{\circ} \mathrm{C}$ and $\mathrm{RH} \geq 90 \%$ & TRH.15T30nRHG90.CHN \\
\hline $9^{\circ} \mathrm{C} \leq \mathrm{T} \leq 30^{\circ} \mathrm{C}$ and $\mathrm{RH} \geq 80 \%$ & TRH.9T30nRHG80.CHN \\
\hline $9^{\circ} \mathrm{C} \leq \mathrm{T} \leq 30^{\circ} \mathrm{C}$ and $\mathrm{RH} \geq 90 \%$ & TRH.9T30nRHG90.CHN \\
\hline $\mathrm{VPD} \leq 0.45 \mathrm{kPa}$ & VPD.L45.CHN \\
\hline \multicolumn{2}{|l|}{ Cumulative number of days } \\
\hline$\overline{\mathrm{RH}}>70 \%^{\mathrm{b}}$ & RH.G70.CD \\
\hline$\overline{\mathrm{RH}}<60 \%$ & RH.L60.CD \\
\hline $14^{\circ} \mathrm{C}<\overline{\mathrm{T}}<22^{\circ} \mathrm{C}$ & T.14T22.CD \\
\hline$\overline{\mathrm{T}}>20^{\circ} \mathrm{C}$ & T.G20.CD \\
\hline$\overline{\mathrm{T}}<9^{\circ} \mathrm{C}$ & T.L9.CD \\
\hline$\overline{\mathrm{VPD}}<0.6 \mathrm{kPa}$ & VPD.L6.CD \\
\hline \multicolumn{2}{|l|}{ Cumulative number of days nighttime } \\
\hline$\overline{\mathrm{RH}}>70 \%$ & RH.G70.CN \\
\hline$\overline{\mathrm{RH}}>90 \%$ & RH.G90.CN \\
\hline$\overline{\mathrm{VPD}}<0.1 \mathrm{kPa}$ & VPD.L1.CN \\
\hline
\end{tabular}

a Variables are grouped by the cumulative number of (nighttime) hours or days in which a specified condition was met. $\mathrm{RH}=$ relative humidity, $\mathrm{T}=$ temperature, $\mathrm{VPD}=$ vapor pressure deficit, and TDD $=$ temperature-dewpoint depression.

b The overbar notation $(\bar{x})$ symbolizes the mean of $x$ estimated over 24 (full day) or 12 (nighttime) hourly values.
Functional summaries. For any given weather variable, a smooth (continuous) penalized functional curve, $x_{n}(t),(n=1, \ldots$, $N$ ), was estimated (see the Appendix for details). Here, the $n$ subscript represents the $n^{\text {th }}$ out of $N=865$ curves for the variable. Penalized cubic B splines were used to estimate the smooth curve. The pointwise functional mean at time $t$ across all $N$ curves for a given weather variable was

$$
\bar{x}(t)=N^{-1} \sum_{n=1}^{N} x_{n}(t)
$$

The pointwise functional standard deviation at $t$ across $N$ curves was

$$
\operatorname{sd}_{x}(t)=\left\{\frac{1}{N-1} \sum_{n=1}^{N}\left(x_{n}(t)-\bar{x}(t)\right)^{2}\right\}^{1 / 2}
$$

Functional means and standard deviations were also estimated for the first derivative functions (equation A3), and separately for the sets of curves associated with FHB epidemics and nonepidemics (236 and 629 curves, respectively).

Standardizations. It can be difficult to ascertain where differences between the mean functional curves associated with FHB epidemics and nonepidemics were of a meaningful magnitude when viewed across time series for the different weather variables, because of the different measurement scales (e.g., ${ }^{\circ} \mathrm{C}$ for $\mathrm{T}$ versus $\mathrm{kPa}$ for VPD). This was true particularly with the cumulative-type series, where the cumulative number of hours meeting some condition could run into the hundreds or thousands. Moreover, differences in mean functional curves do not reflect the degree of overlap of the individual epidemic and nonepidemic curves across all $N$ observations. Thus, standardization of the functional means can be used as a visual tool, considering differences in measurement scale and overlap.

For a given weather variable, let $\bar{x}_{\text {epi }}(t)$ be the pointwise functional mean for the set of functional curves associated with FHB epidemics, and $\bar{x}_{\text {nonepi }}(t)$ be the pointwise functional mean for the set of functional curves associated with FHB nonepidemics. Then the standardized pointwise functional mean for the curves associated with FHB epidemics was

$$
\bar{x}_{\text {epi }}^{\mathrm{std}}(t)=\frac{\bar{x}_{\text {epi }}(t)-\bar{x}(t)}{\operatorname{sd}_{x}(t)}
$$

and the standardized pointwise functional mean for the curves associated with FHB nonepidemics was

$$
\bar{x}_{\text {nonepi }}^{\text {std }}(t)=\frac{\bar{x}_{\text {nonepi }}(t)-\bar{x}(t)}{\operatorname{sd}_{x}(t)}
$$

The standardized pointwise functional mean curves associated with FHB epidemics and nonepidemics represented rescaled deviations from the overall mean functional curve $\bar{x}(t)$. The difference between $\bar{x}_{\text {epi }}^{\text {std }}(t)$ and $\bar{x}_{\text {nonepi }}^{\text {std }}(t)$, obtained by subtracting equation $3 \mathrm{~b}$ from equation $3 \mathrm{a}$ was $\frac{\bar{x}_{\mathrm{epi}}(t)-\bar{x}_{\text {nonepi }}(t)}{\mathrm{sd}_{x}(t)}$.

In an analogous manner, let $\operatorname{sd}_{x, \text { epi }}(t)$ and $\operatorname{sd}_{x}$, nonepi $(t)$ be the pointwise functional standard deviations of the curves associated with FHB epidemics and nonepidemics, respectively (calculated from equation 2 for epidemics and nonepidemics separately). Then the difference between the standardized versions of $\operatorname{sd}_{x, \text { epi }}(t)$ and $\operatorname{sd}_{x, \text { nonepi }}(t)$ was $\frac{\operatorname{sd}_{x, \text { epi }}(t)-\operatorname{sd}_{x, \text { nonepi }}(t)}{\operatorname{sd}_{x}(t)}$.

Function-on-scalar modeling. After each $x(t)$ was represented by a smooth function, there was interest in determining whether variation in $x(t)$ was associated with FHB epidemics or nonepidemics. To address this question, a function-on-scalar regression model (Morris 2015; Ramsay and Silverman 2005) 


$$
x_{i j}(t)=\mu(t)+(-1)^{i} \beta(t)+\varepsilon_{i j}(t)
$$

was used for the $j^{\text {th }}$ observation in the $i^{\text {th }}$ group, where $i=1,2$ indexed the FHB nonepidemic and epidemic groups, respectively. Note that the $n$ subscript (equations A1 and A2) for the $n^{\text {th }}$ series (out of $N$ ) is replaced by the $i j$ subscript to account for group and observation within group. The grand mean at $t$ was $\mu(t)$ and $\varepsilon_{i j}(t)$ was the residual error. The scalar multiplying $\beta(t)$ assumed the value 1 if the observation was from an epidemic and -1 if from a nonepidemic. Therefore, in this formulation, the $\beta(t)$ represented the time trend of the mean difference between epidemics and nonepidemics for the functional curves (Ramsay et al. 2009). The construction of confidence intervals for $\beta(t)$ is more complicated than can be described here but involves accounting for both the variation of the smoothed $x_{i j}(t)$ about their predicted values and the residuals due to smoothing the original data itself (Ramsay and Silverman 2005). Because the covariate was a scalar coding for two levels (epidemic and nonepidemic), equation 4 is also described as a so-called functional analysis of variance.

A functional $t$ test was used to determine whether there was statistically significant separation of $\bar{x}_{\text {epi }}(t)$ and $\bar{x}_{\text {nonepi }}(t)$, which was equivalent to addressing whether $\beta(t) \neq 0$. An absolute value of a $t$ statistic was given by

$$
F T(t)=\frac{\left|\bar{x}_{\text {epi }}(t)-\bar{x}_{\text {nonepi }}(t)\right|}{\sqrt{\frac{1}{N_{\text {epi }}} \operatorname{var}_{x, \text { epi }}(t)+\frac{1}{N_{\text {nonepi }}} \operatorname{var}_{x, \text { nonepi }}(t)}}
$$

where $\operatorname{var}_{x, \text { epi }}(t)$ and $\operatorname{var}_{x \text {,nonepi }}(t)$ were the functional variances (square of the functional standard deviations; see equation 2 ) of the $x(t)$ associated with FHB epidemics and nonepidemics, respectively; and $N_{\text {epi }}$ and $N_{\text {nonepi }}$ were the number of curves associated with FHB epidemics and nonepidemics, respectively, where $N=$ $N_{\text {epi }}+N_{\text {nonepi }}$. The test statistic was $\max [F T(t)]$. The critical value of $\max [F T(t)]$ was determined by permutation, because $\max [F T(t)]$ does not have an analytically defined statistical distribution under the null hypothesis of no difference between the two groups. For the permutations, the functionally represented curve labels were randomly shuffled and $\max [F T(t)]$ recalculated after each shuffle (Ramsay et al. 2009). This procedure allowed the construction of the null distribution of $\max [F T(t)]$ against which to evaluate the observed value of $\max [F T(t)]$. The $F T(t)$ were evaluated at the hourly or daily observational time points for the respective series. For series in which the underlying $t$ was daily, 1,000 permutations were done; 200 permutations were done when $t$ was hourly, to reduce computational time. Observed values of $\max [F T(t)]$ above the 95th quantile of the null distribution were considered indicative of a statistical separation between $\bar{x}_{\text {epi }}(t)$ and $\bar{x}_{\text {nonepi }}(t)$.

Functional modeling of the data were done using the $\mathrm{R}$ fda package (version 2.4.4). Function-on-scalar regression was done with the fosr function in the $\mathrm{R}$ refund package (version 0.1-14). Time series data and their functional representations were visualized using ggplot2 (version 2.2.1).

Although a wide range of weather variable types were analyzed functionally, space does not permit describing each variable individually. In the Results, we will focus on a subset of the variables chosen to illustrate key general findings, and their connections to our previous research and to published articles in the FHB arena (the full set is shown in Supplementary File S1). T.A (daily mean T), RH.A (daily mean RH), and TRH.15T30nRHG80.CHD (cumulative number of hours in which $15^{\circ} \mathrm{C} \leq \mathrm{T} \leq 30^{\circ} \mathrm{C}$ and $\mathrm{RH} \geq 80 \%$ ) were identified by our previous work (Shah et al. 2013, 2014) as variables associated with FHB epidemics. VPD.L635.CHD (cumulative number of hours in which VPD $\leq 0.635 \mathrm{kPa}$ ) is associated with peak discharges of $F$. graminearum ascospores (Manstretta and Rossi 2015). The variable VPD.L6.CD (cumulative number of days in which mean daily VPD $<0.6 \mathrm{kPa}$ ) is one way of recasting VPD.L635.
CHD but from a daily (as opposed to hourly) perspective. T. MINMAXDIFF (difference between the daily minimum and maximum T) and RH.90P (daily 90th percentile of RH) are variables we had not considered before (Shah et al. 2013, 2014) but were suggested by FHB work from Belgium (Landschoot et al. 2012,2013 b) as ways of quantifying the effects of weather variance or extrema on epidemics. Manstretta and Rossi (2016) identified $5^{\circ} \mathrm{C} \leq \mathrm{T} \leq 30^{\circ} \mathrm{C}$ and $\mathrm{RH} \geq 75 \%$ as favoring the production of $F$. graminearum perithecia. We examined one version of this variable (TRH.5T30nRHG75.CHD). The variable T.L9.CHD is associated with suppressing the development of $F$. graminearum perithecia in the field (Andries et al. 2000); low temperatures generally limit or delay their formation and maturation (Dufault et al. 2006). RH.G70.CD (cumulative number of days in which mean daily $\mathrm{RH}>70 \%$ ) was proposed as a variable potentially associated with FHB based on partial dependence plots from boosted regression trees (Shah et al. 2014), and is associated with toxin accumulation in oat grain (Xu et al. 2014).

\section{RESULTS}

Individual smooth curves. The smoothed functional curves for six of the weather variables described above, beginning from 120 days pre-anthesis to 20 days post-anthesis, are shown in Figure 1, with separate panels for the FHB epidemic and nonepidemic groups. There was much variability among the individual curves, even after penalized smoothing. Cumulative-type variables showed increasing variance from the initial point of accumulation (120 days pre-anthesis) onward. Some conditions-for example, the one represented by TRH.15T30nRHG80.CHD-were difficult to meet until later in the growing season (Fig. 1C).

Functional means and standard deviations. The smoothed functional means for the same six weather variables shown in Figure 1, beginning from 120 days pre-anthesis to 20 days postanthesis, are shown in Figure 2, where the functional means were estimated separately for the FHB epidemic and nonepidemic groups but plotted in the same panels. With the moisture-related variables (Fig. 2D, G, J, and P), consistent separation between the epidemic and nonepidemic functional means began as early as 40 days preanthesis (Fig. 2E, H, K, and Q). The functional means for daily average T (Fig. 2A) increased approximately linearly over the 140day period, an intuitive feature that escaped attention earlier when focusing on much shorter time periods (Shah et al. 2013, 2014); however, there was little and inconsistent separation between the epidemic and nonepidemic daily $\mathrm{T}$ functional means (Fig. 2B). Regarding T, a more consistent separation between the functional means for epidemics and nonepidemics was seen in the daily difference between the maximum and minimum T (Fig. 2M and $\mathrm{N}$ ). The functional standard deviations of the T-related variables (Fig. 2C and $\mathrm{O}$ ) indicated less variability leading up to anthesis but there were no clear differences between the mean functional standard deviations of the epidemic and nonepidemic groups. By contrast, less functional variability in the 90th percentile for daily $\mathrm{RH}$ was seen with epidemics than with nonepidemics (Fig. 2R), beginning approximately 40 days pre-anthesis. With the cumulative-type variables, functional standard deviations increased from the 120-day pre-anthesis start of recording (Fig. 2I and $\mathrm{L}$ ), as expected from the visualization of the individual curves (Fig. 1C and D).

Standardizations. Visual comparisons across different variables were possible after standardization (Fig. 3). The mean standardized functional curves associated with epidemics and nonepidemics (Fig. 3A, D, G, J, M, and P) now represented scaled deviations from the overall mean function. Values close to 0 corresponded to large overlap in the individual functional curves of the two groups. Among the moisture-related series, the difference (appearing at approximately 40 days pre-anthesis) between the standardized functional means for epidemics and nonepidemics was larger for the 
daily mean variables (Fig. 3E and Q) than for the cumulative-type variables (Fig. $3 \mathrm{H}$ and $\mathrm{K}$ ). Lower daily $\mathrm{T}$ fluctuations (Fig. $3 \mathrm{~N}$ ) beginning approximately 40 days pre-anthesis were more consistently associated with FHB epidemics than average daily T (Fig. 3B). The difference between the standardized functional standard deviations of the curves associated with epidemics and nonepidemics reflected a lower variability, with epidemics, in daily average RH (Fig. 3F) and daily 90th percentile of RH (Fig. 3R) in the 40-day period leading up to anthesis, in addition to the functional means being well-separated (Fig. 3E and Q).

First derivative functions. Functional first derivatives were particularly useful with cumulative-type variables for addressing whether the rate of accumulation of given conditions was higher (lower) where FHB epidemics had occurred as opposed to nonepidemics. The first-derivative analysis was also done on the noncumulative weather series (unpublished) but the results provided little
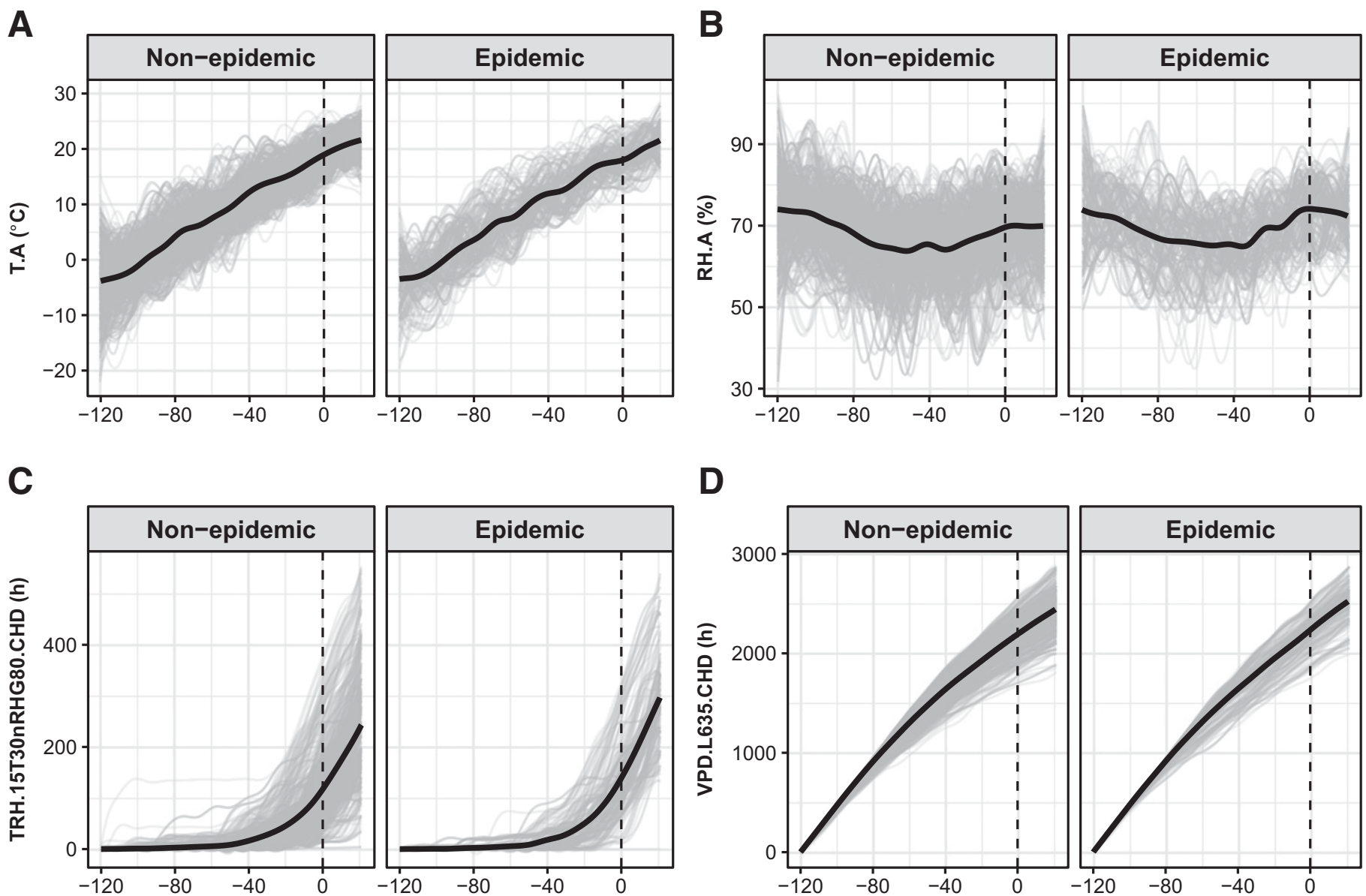

D
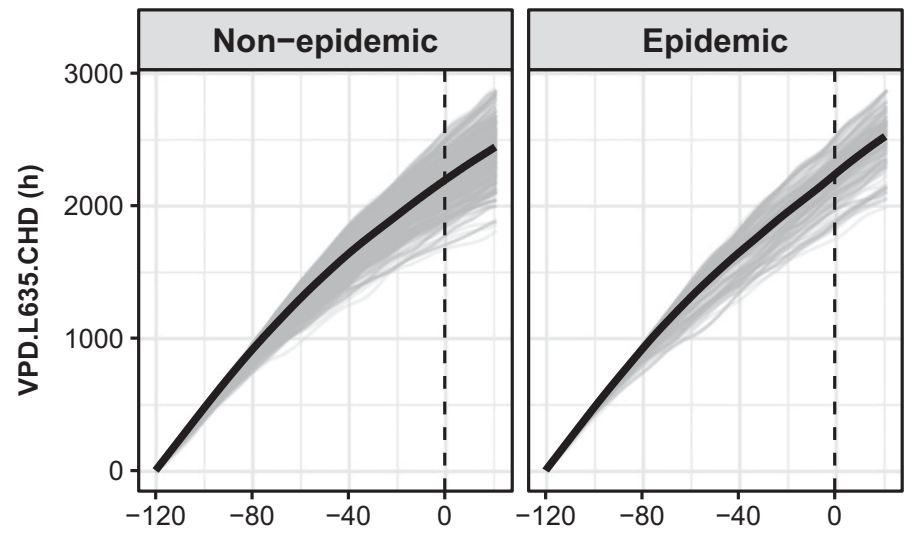

$\mathbf{E}$

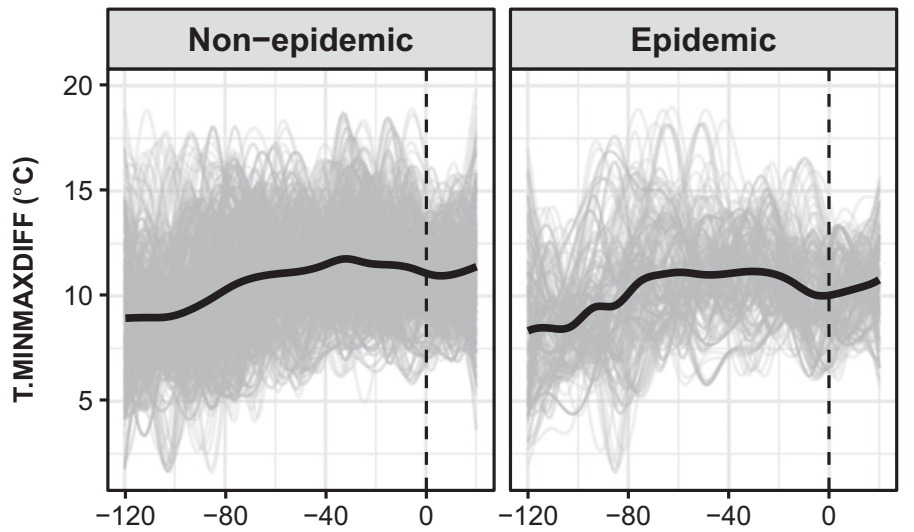

$\mathbf{F}$

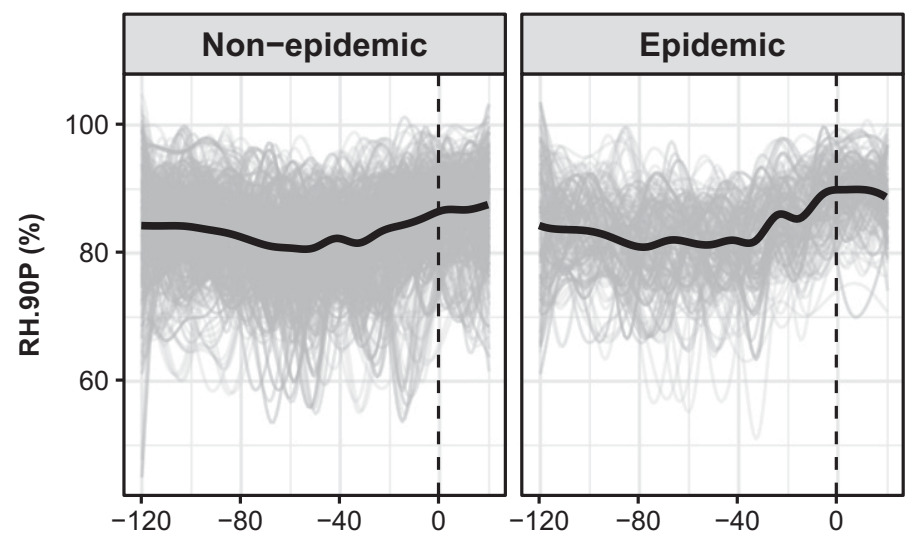

Days relative to anthesis

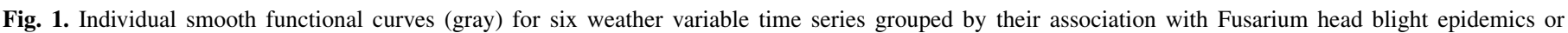

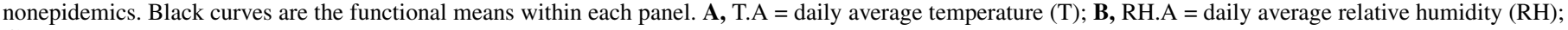

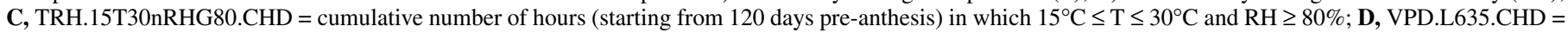

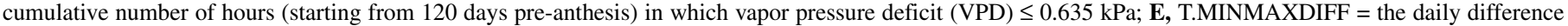
between the maximum and minimum observed hourly T; and F, RH.90P = the daily 90th percentile of observed hourly RH. 


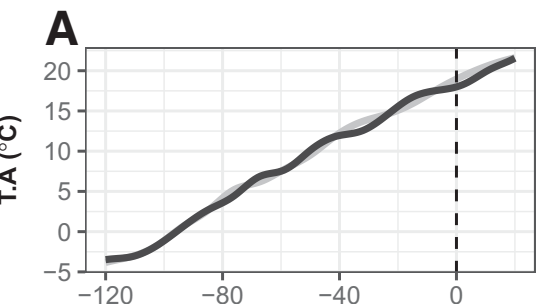

D

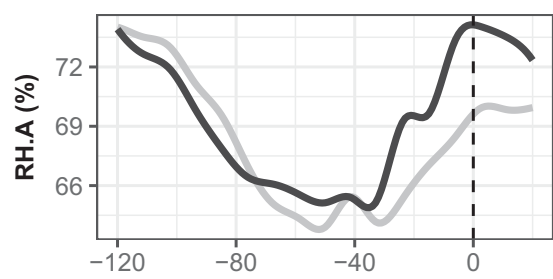

玉 $\mathbf{G}$
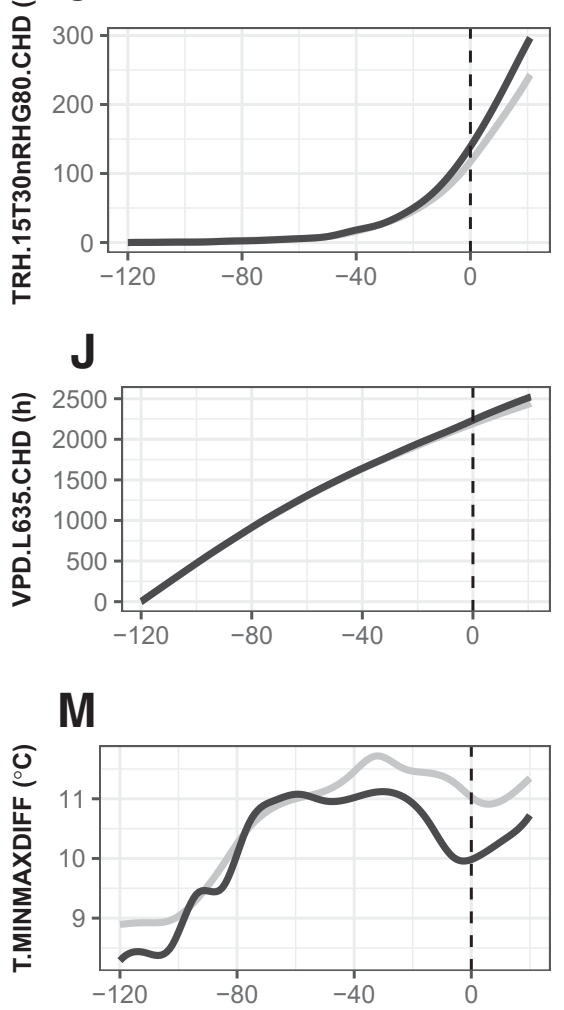

\section{P}

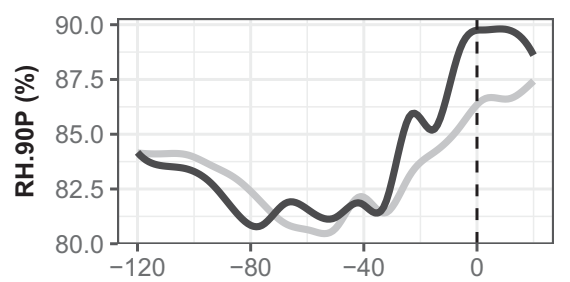

B

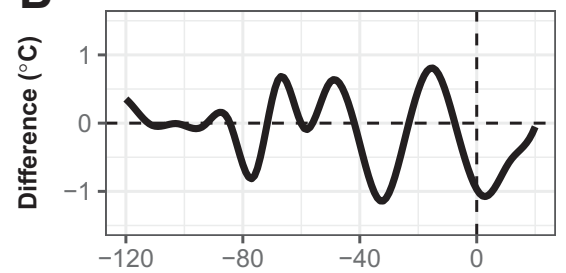

E

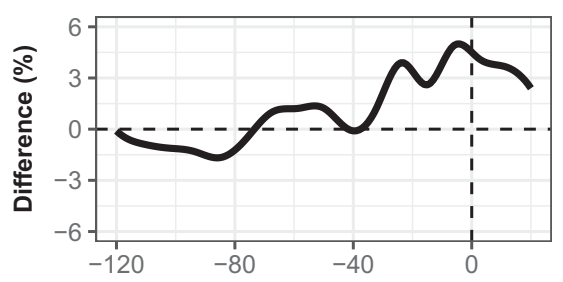

H

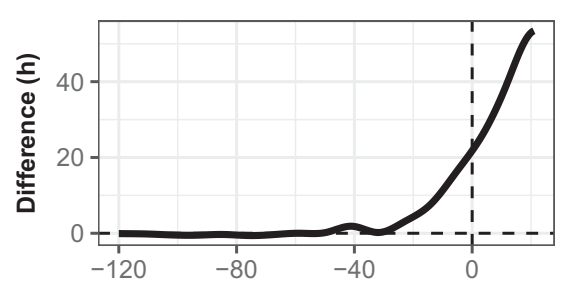

K

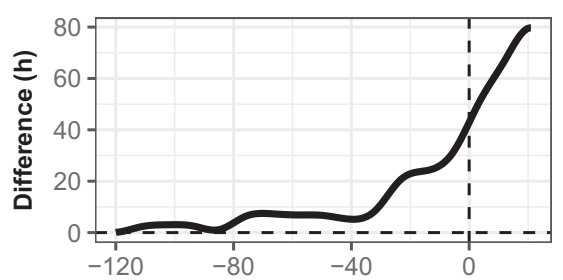

$\mathbf{N}$

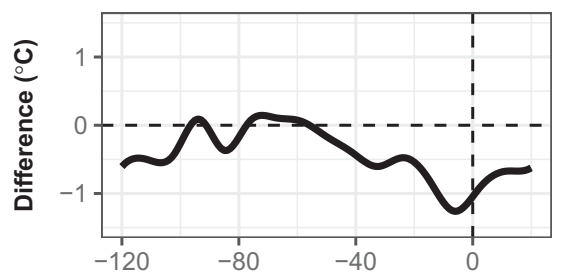

Q

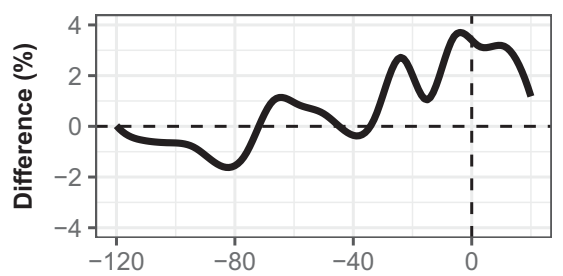

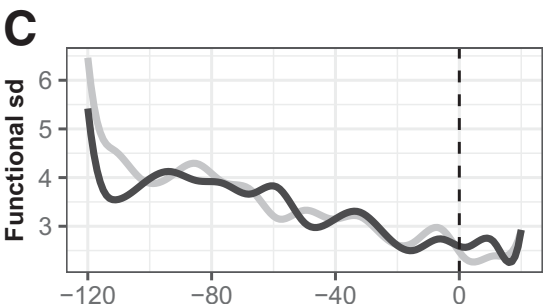

F

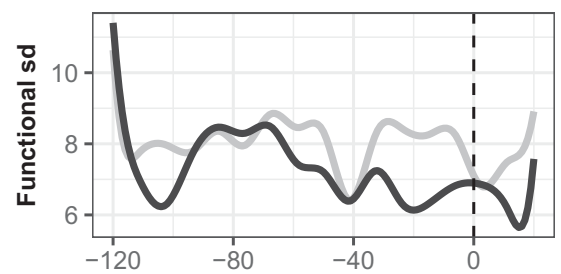

I

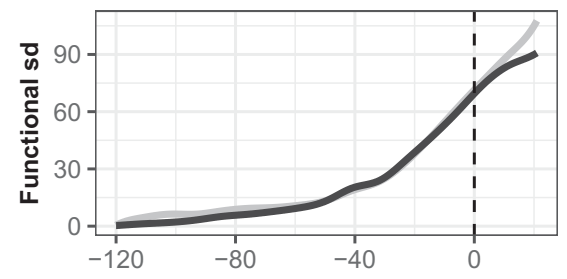

L

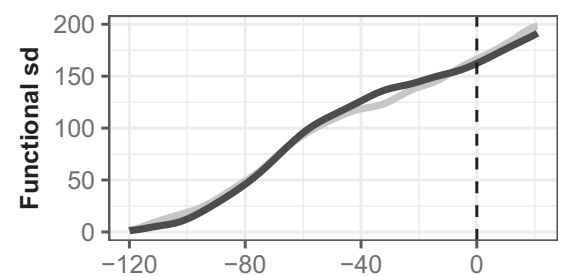

0

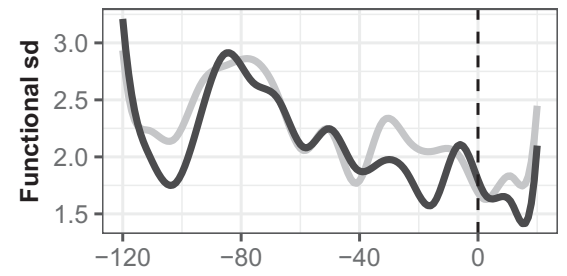

R

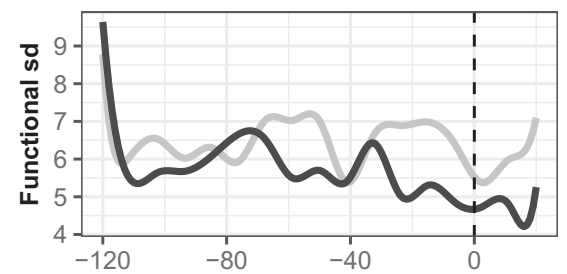

\section{Days relative to anthesis}

Fig. 2. A, D, G, J, M, and P, Functional means of six different weather variables linked to Fusarium head blight (FHB) observations, from 120 days pre-anthesis to 20 days post-anthesis. Means were estimated separately for the two classes: FHB epidemics (black lines) and nonepidemics (gray lines). B, E, H, K, N, and $\mathbf{Q}$, Differences (epidemic - nonepidemic) between the functional means shown in the first column of panels. $\mathbf{C , ~ F , ~ I , ~ L , ~ O , ~ a n d ~ R , ~ F u n c t i o n a l ~ s t a n d a r d ~ d e v i a t i o n s ~ f o r ~}$ the epidemic and nonepidemic classes. T.A $=$ daily average temperature $(\mathrm{T})$, RH.A $=$ daily average relative humidity $(\mathrm{RH}), \mathrm{TRH} .15 \mathrm{~T} 30 \mathrm{nRHG} 80 . \mathrm{CHD}=$ cumulative number of hours (starting from 120 days pre-anthesis) in which $15^{\circ} \mathrm{C} \leq \mathrm{T} \leq 30^{\circ} \mathrm{C}$ and $\mathrm{RH} \geq 80 \%$, VPD.L635.CHD $=$ cumulative number of hours (starting from 120 days pre-anthesis) in which vapor pressure deficit (VPD) $\leq 0.635 \mathrm{kPa}$, T.MINMAXDIFF $=$ the daily difference between the maximum and minimum observed hourly T, and RH.90P = the daily 90th percentile of observed hourly RH. 
A

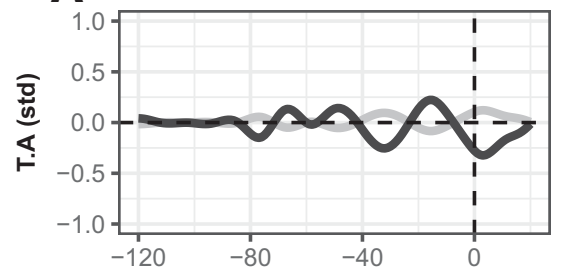

D
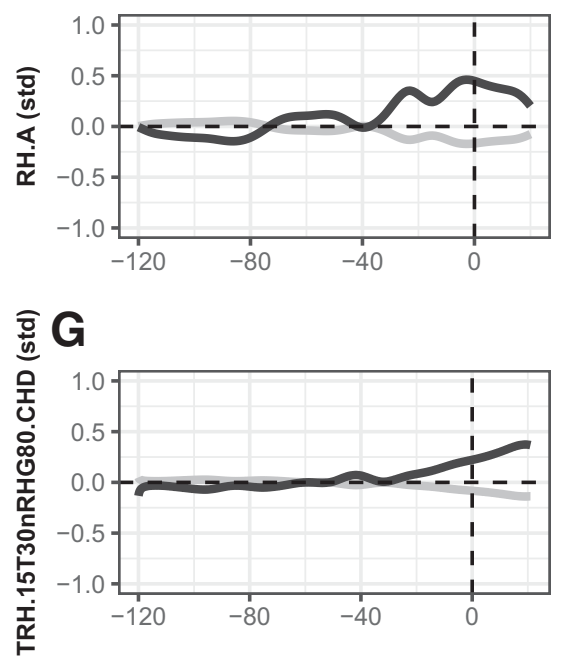

J

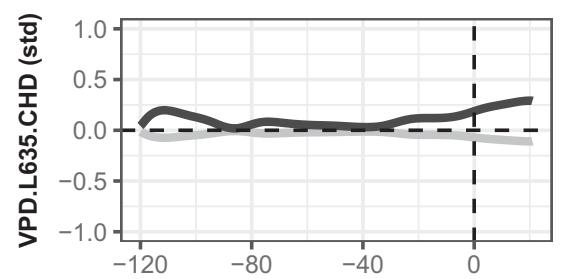

M

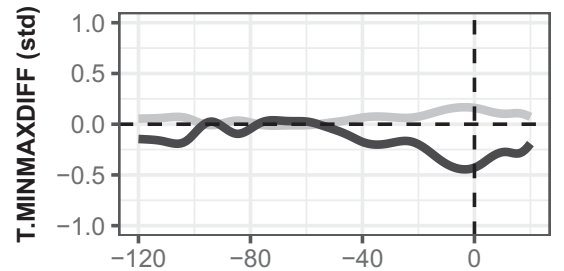

P

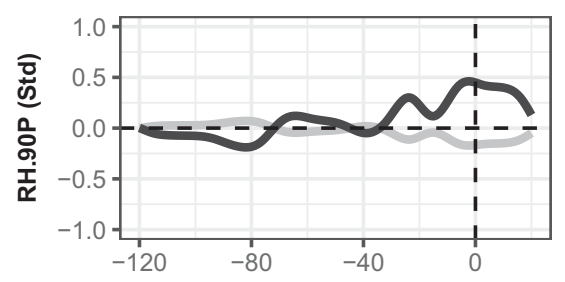

B

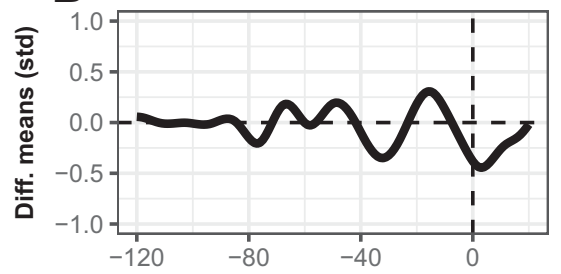

E

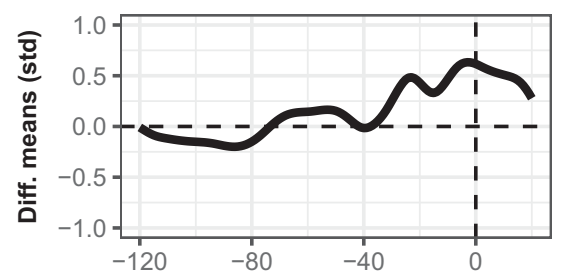

H

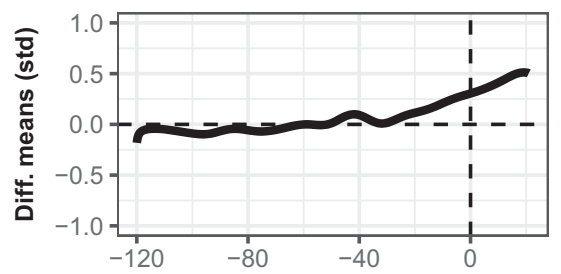

K

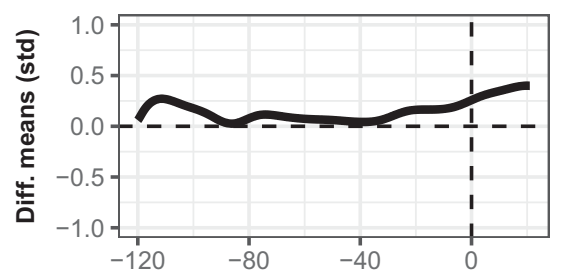

N

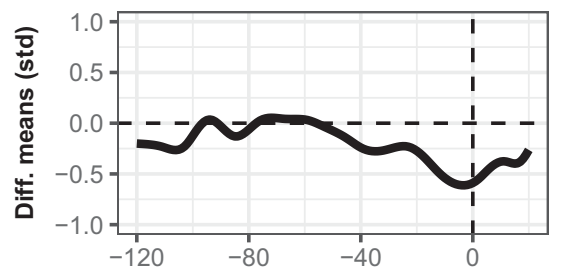

Q

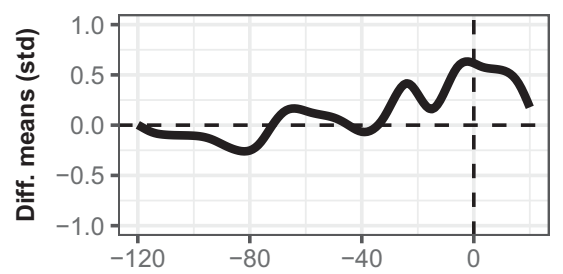

C

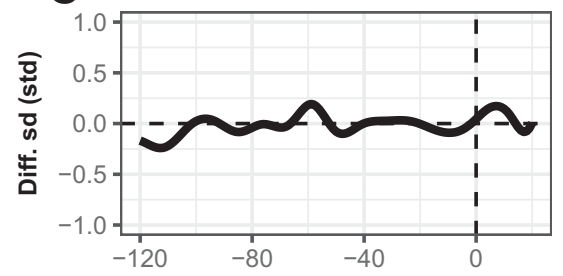

F

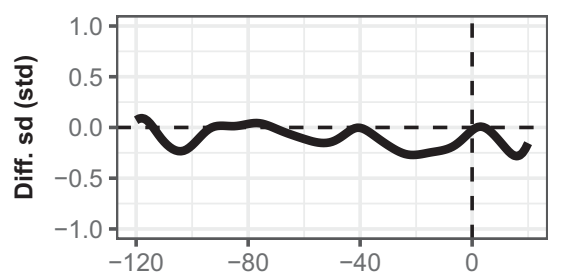

I

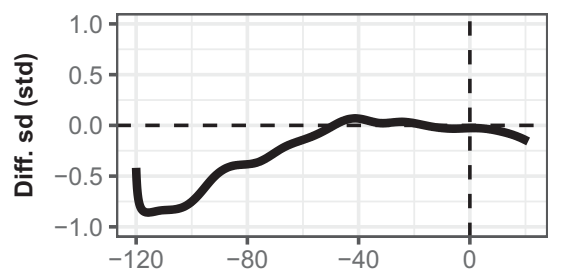

$\mathbf{L}$

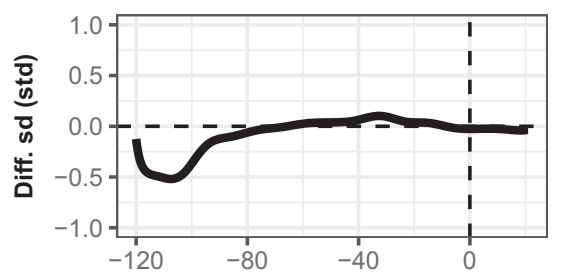

O

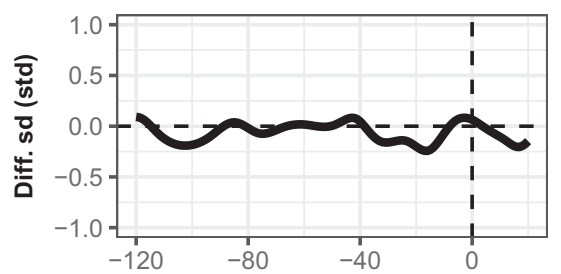

R

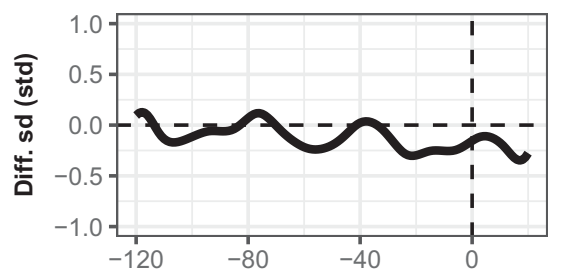

\section{Days relative to anthesis}

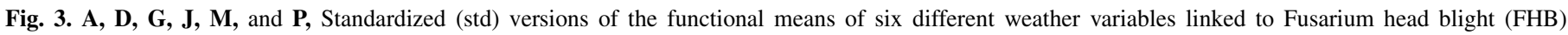

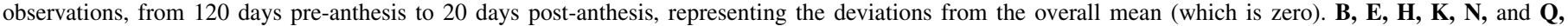

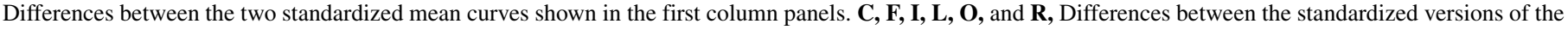

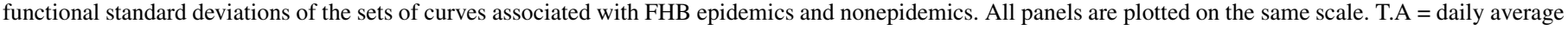

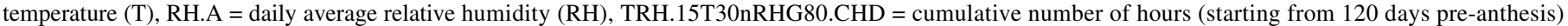

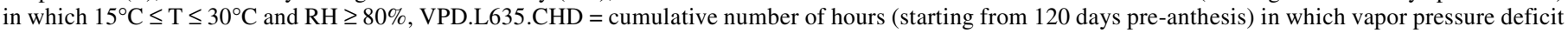

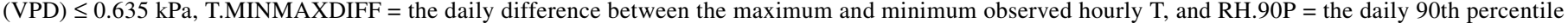
of observed hourly RH. 
A

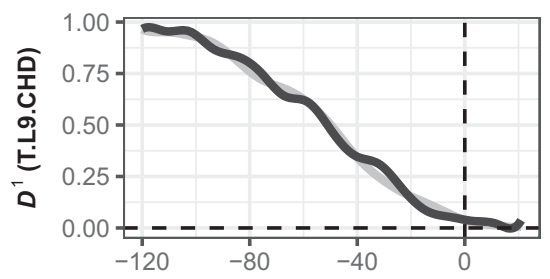

\section{D}
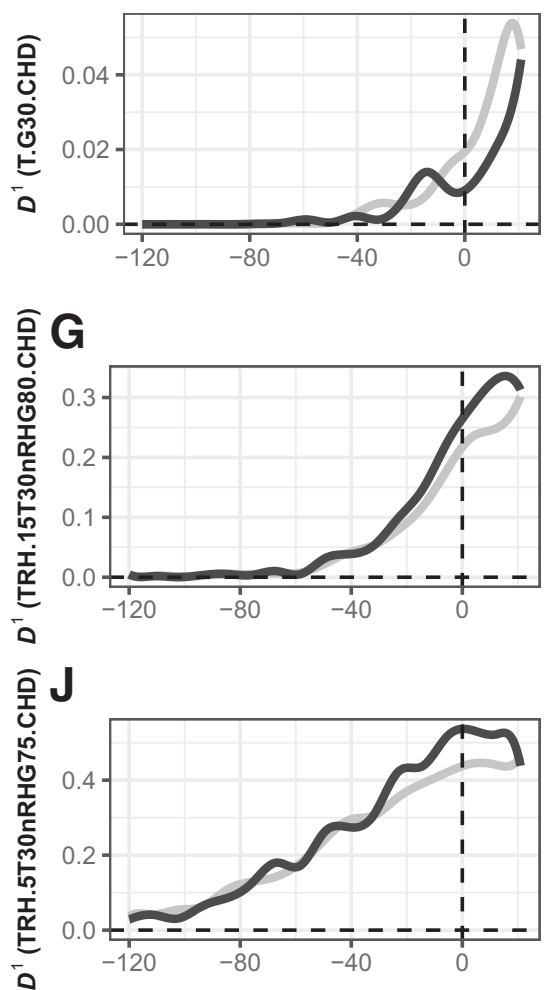

M

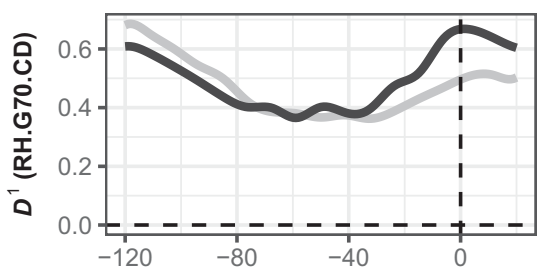

\section{$\mathbf{P}$}

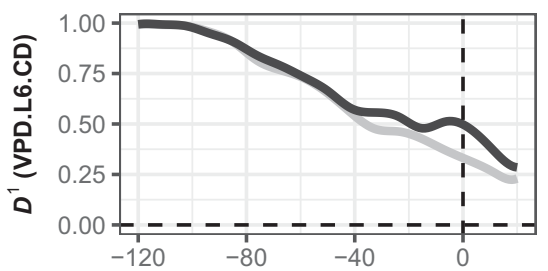

B

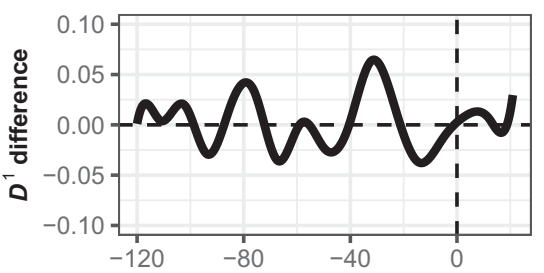

E

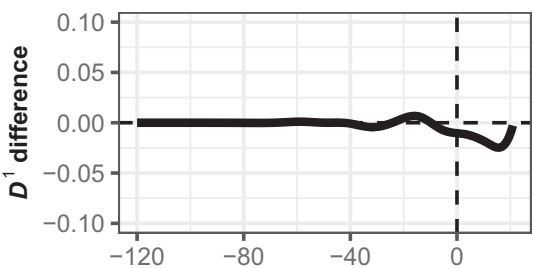

H

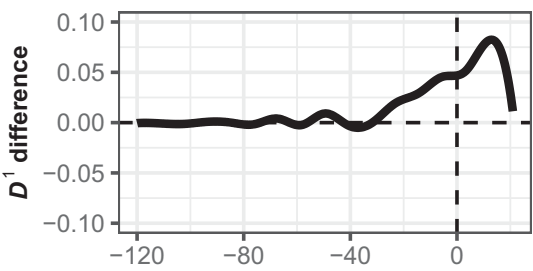

K

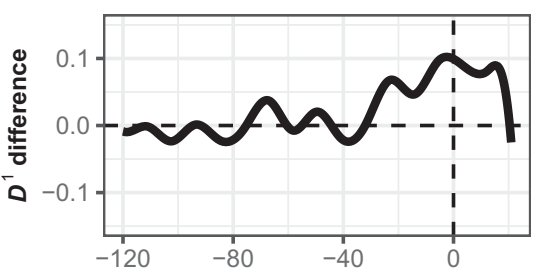

\section{N}

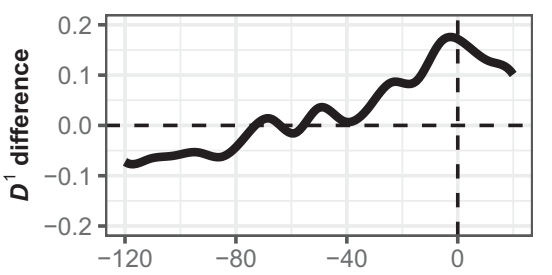

Q

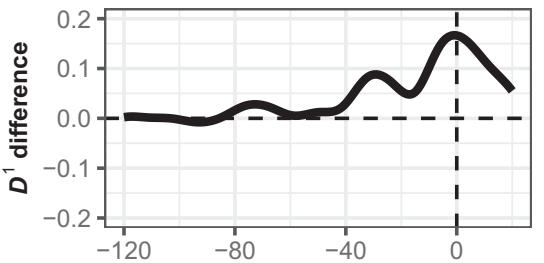

C

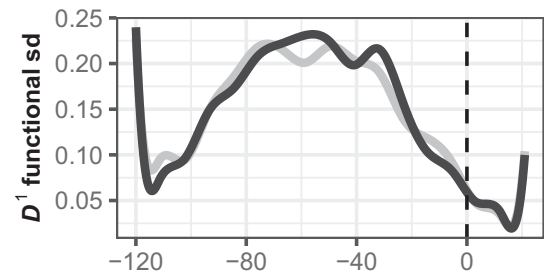

$\mathbf{F}$

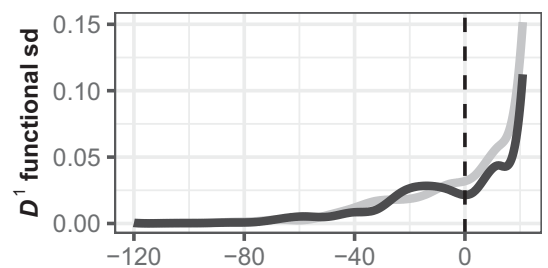

I

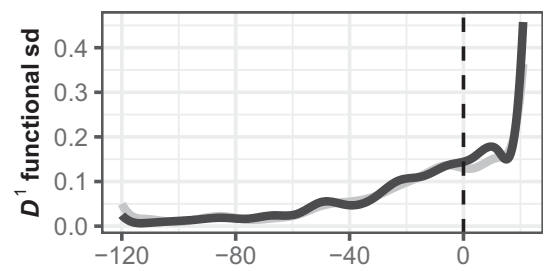

$\mathbf{L}$

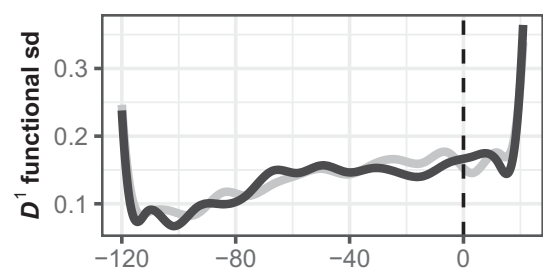

0

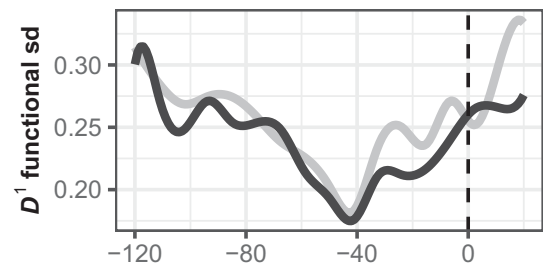

R

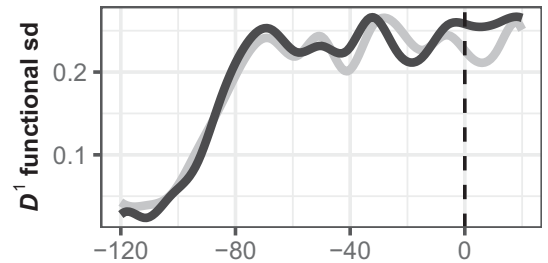

\section{Days relative to anthesis}

Fig. 4. A, D, G, J, M, and $\mathbf{P}$, Functional first derivative $\left(D^{1}\right)$ means of six different weather variables linked to Fusarium head blight (FHB) observations. $D^{1}$ means were estimated separately for the two classes of observations: FHB epidemics (black lines) and nonepidemics (gray lines). B, E, H, K, N, and $\mathbf{Q}$, Differences (epidemic - nonepidemic) between the curves shown in the first column of panels. $\mathbf{C}, \mathbf{F}, \mathbf{I}, \mathbf{L}, \mathbf{O}$, and $\mathbf{R}$, Functional standard deviations of the first derivative curves associated with the epidemic and nonepidemic classes. Each variable (on which $D^{1}$ means were estimated) represented the cumulative number of hours (ch) or days (cd) in which the specified condition was met, from 120 days pre-anthesis to 20 days post-anthesis. T.L9.CHD $=$ ch temperature $(\mathrm{T})<9^{\circ} \mathrm{C}, \mathrm{T} . \mathrm{G} 30 . \mathrm{CHD}=\mathrm{ch} \mathrm{T}>$ $30^{\circ} \mathrm{C}$, TRH.15T30nRHG80.CHD $=\operatorname{ch~} 15^{\circ} \mathrm{C} \leq \mathrm{T} \leq 30^{\circ} \mathrm{C}$ and relative humidity $(\mathrm{RH}) \geq 80 \%$, TRH.5T30nRHG75.CHD $=\mathrm{ch} 5^{\circ} \mathrm{C} \leq \mathrm{T} \leq 30^{\circ} \mathrm{C}$ and $\mathrm{RH} \geq 75 \%$, RH. G70.CD $=$ cd daily mean RH $>70 \%$, VPD.L6.CD $=$ cd daily mean vapor pressure deficit (VPD) $<0.6 \mathrm{kPa}$. With cumulative-type variables, $D^{1}$ (the rate of accumulation) is strictly $\geq 0$, and this feature is reflected in the $y$-axes of the first column of panels. 
insight. The analysis of functional first derivatives is illustrated with six weather variables (Fig. 4).

T.L9.CHD and T.G30.CHD represented unfavorable T conditions (extrema). There were no appreciable differences between epidemics and nonepidemics in the rate of accumulation of hours in which $\mathrm{T}<9^{\circ} \mathrm{C}$ (Fig. 4A and B). However, the rate of accumulation of hours in which $\mathrm{T}>30^{\circ} \mathrm{C}$ was slower for epidemics just before anthesis and continuing into the post-anthesis period (Fig. 4D and E). With the moisture-related variables (Fig. 4G, J, M, and P), their rates of accumulation were higher for epidemics than for nonepidemics beginning approximately 40 to 60 days pre-anthesis. As time progressed from 120 days pre-anthesis toward anthesis, the VPD.L6.CD condition was met less often in general (Fig. 4P), more so with nonepidemics than with epidemics (Fig. 4Q). There weren't any clearly discernable, consistent patterns in the functional standard deviations of the first derivative functions (Fig. 4C, F, I, $\mathrm{L}, \mathrm{O}$, and 4R).

Function-on-scalar regression. On daily (and cumulative) series. The model specified by equation 4 was fit to the functional curves shown in Figure 1, with the objective of determining whether there were statistical differences between the curves associated with FHB epidemics or nonepidemics. For each of the six variables, the overall mean $\mu(t)$ and the time trend of the difference between epidemics and nonepidemics $\beta(t)$ are shown (Fig. 5A, B, C, G, H, and I). Plots of the observed test statistic $\max [F T(t)]$ of the functional $t$ test are shown in Figure 5D, E, F, J, K, and L, with the critical value indicated by the dashed line. Values of $\max [F T(t)]$ above the dashed critical value line indicate regions of the time series where the functional parameter, $\beta(t)$, was significantly different from 0 (at $P<0.05$ ) and, hence, interpreted as a statistical difference between the time series of the weather variable in relation to epidemics and nonepidemics.

With the T-related variables (Fig. 5A and $\mathrm{H}$ ), a more consistent separation between the functional means for epidemics and nonepidemics was seen in the daily difference between minimum and maximum $\mathrm{T}$ (Fig. 5K) than with average daily $\mathrm{T}$ (Fig. 5D). Moisture-related variables (Fig. 5B, C, G, and I) all indicated a significantly higher functional mean for epidemics, beginning within the 40-day pre-anthesis period and continuing post-anthesis (Fig. 5E, F, J, and L).

On functional first derivatives. The mean rate of accumulation of hours in which $\mathrm{T}<9^{\circ} \mathrm{C}$ (i.e., derivative of T.L9.CHD) kept decreasing over the 140-day period examined (Fig. 6A), which intuitively reflected rising daily minimum temperatures during the spring and summer months. As days become progressively warmer from spring onward, it is more difficult for this temperature condition to be met. There was no consistent temporal separation between epidemics and nonepidemics in the rate of accumulation of T.L9.CHD (Fig. 6D). In contrast to T.L9.CHD, T.G30.CHD (accumulation of hours in which $\mathrm{T}$ exceeded $30^{\circ} \mathrm{C}$ ) was met with increasing frequency from 50 days pre-anthesis onward (Fig. 6B) but the rate of accumulation was statistically lower for epidemics beginning around anthesis to approximately 15 days post-anthesis (Fig. 6E). Note that the $x$-axes of Figure 6B and $\mathrm{E}$ begin at 50 days pre-anthesis (not 120 days pre-anthesis), because there was no accumulation of the T.G30.CHD condition prior to approximately 60 days pre-anthesis because temperatures were still relatively cool (Fig. 4D and E), and the long trail of zero data led to matrix singularity issues. Therefore, the data were truncated to 50 days preanthesis before fitting equation 4 . The rate of accumulation of TRH.15T30nRHG80.CHD (cumulative hours in which $\mathrm{T}$ was between 15 and $30^{\circ} \mathrm{C}$, with $\mathrm{RH} \geq 80 \%$ ) began to increase rapidly beginning approximately 40 days pre-anthesis (Fig. 6C), and was statistically higher for epidemics from approximately 10 days preanthesis to 10 days post-anthesis (Fig. 6F). The rate at which the TRH.5T30nRHG75.CHD condition was met (cumulative hours in which T was between 5 and $30^{\circ} \mathrm{C}$, with $\mathrm{RH} \geq 75 \%$; associated with perithecia production) increased steadily from approximately
80 days pre-anthesis to anthesis (Fig. 6G). The $\beta(t)$ fitted coefficient indicated that the rate of accumulation of this variable was consistently higher for epidemics beginning approximately 40 days pre-anthesis, and was statistically higher for epidemics approximately 30 days pre-anthesis to 10 days post-anthesis (Fig. $6 \mathrm{~J}$ ). The rate of accumulation of days in which mean $\mathrm{RH}>70 \%$ was statistically higher for epidemics from approximately 30 days preanthesis through to 20 days post-anthesis (Fig. $6 \mathrm{H}$ and $\mathrm{K}$ ). Overall, it became more difficult for the VPD.L6.CD condition to be met as time progressed from 120 days pre-anthesis toward anthesis (Fig. 6I), because VPD generally increased over the 140 days. However, the rate of accumulation of VPD.L6.CD (associated with $F$. graminearum peak ascospore discharges) for epidemics was statistically higher than for nonepidemics, beginning approximately 30 days pre-anthesis (Fig. 6L). Coincidentally, the maximum difference in the rate of accumulation of VPD.L6.CD between epidemics and nonepidemics was right at anthesis (Fig. 6I and $\mathrm{L}$ ).

\section{DISCUSSION}

In this article, we explored the relationship between weather time series and FHB with FDA (Ramsay and Silverman 2005). Discrete weather (hourly or daily) observations were used to find smooth functions modeling the underlying continuous process (Ramsay and Silverman 2005). An analysis of the functionally represented time series confirmed some prior findings (Manstretta and Rossi 2016; Shah et al. 2013, 2014) and led to novel insights into the relationship between weather and FHB epidemics. Overall, our results confirmed that atmospheric-moisture variables (such as $\mathrm{RH}$ ) were considerably different between epidemics and nonepidemics but also showed that consistent and stable differences in several weather variables, including some cumulative variables and some variables reflecting variation in temperature, started to be manifested as early as 40 days pre-anthesis and carried through the post-anthesis period.

Average daily T, as well as daily maximum T, were lower for FHB epidemics compared with nonepidemics from approximately 10 days pre-anthesis to 10 days post-anthesis. The functional analysis suggested, however, that average daily $\mathrm{T}$, despite having some relevance as a predictor of FHB (Shah et al. 2013, 2014), may not be the best summary of $\mathrm{T}$ conditions for discriminating FHB epidemics from nonepidemics. Any difference between the mean functional curves of daily average $\mathrm{T}$ for epidemics and nonepidemics was relatively small (as reflected in the standardized differences) and confined to narrow windows around anthesis. A better $\mathrm{T}$ summary was the daily difference between the maximum and minimum observed hourly $\mathrm{T}$ values (T.MINMAXDIFF), a variable suggested by FHB modeling results from Belgium (Landschoot et al. 2013b), and for which a consistent separation between the mean functional curves associated with FHB epidemics and nonepidemics appeared as early as 40 days preanthesis. The same separation trend was seen with other variables measuring the daily variability in $\mathrm{T}$ (e.g., the difference between the 90th and 10th percentiles), indicating that, on average, $\mathrm{T}$ became less variable approaching anthesis in epidemic situations. The mean daily difference between maximum and minimum $\mathrm{T}$ was lower for FHB epidemics beginning approximately 50 days pre-anthesis and continuing into the post-anthesis period. It is possible that temperature stability associated with FHB epidemics in the weeks leading up to anthesis may be linked to extended overcast or rainy periods during that time.

Clearer differences between the mean functional curves associated with epidemics and nonepidemics were observed, in general, with the moisture-related weather variables, consistent with earlier research (De Wolf et al. 2003; Kriss et al. 2010; Shah et al. 2013, 2014). This can be seen from graphs of differences between the functional means, standardized means, and the estimated $\beta(t)$ 
A

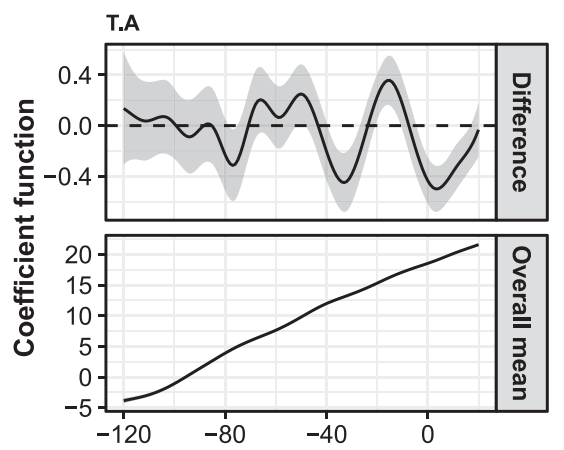

D

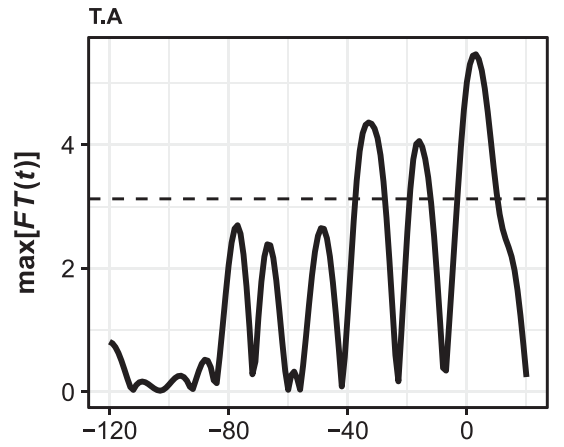

G

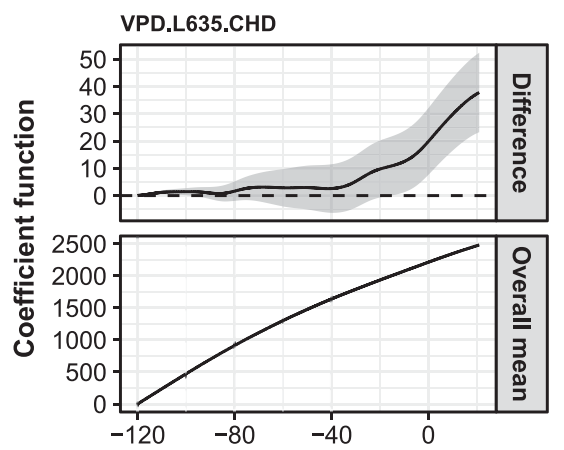

J

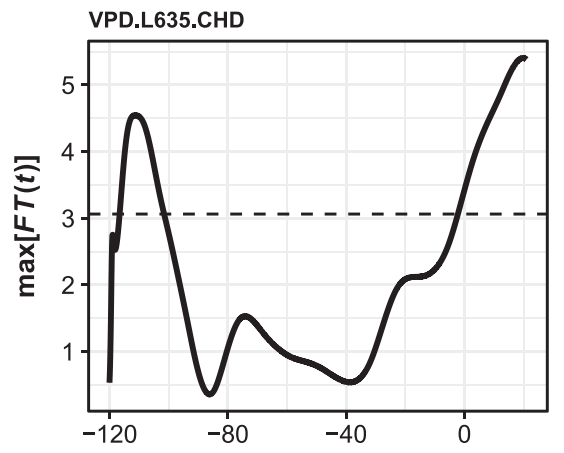

B

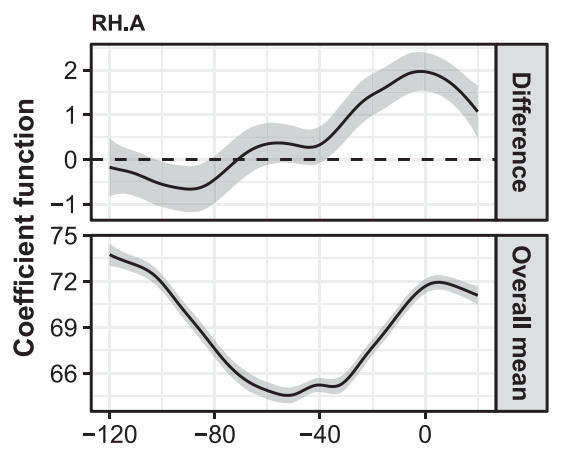

E

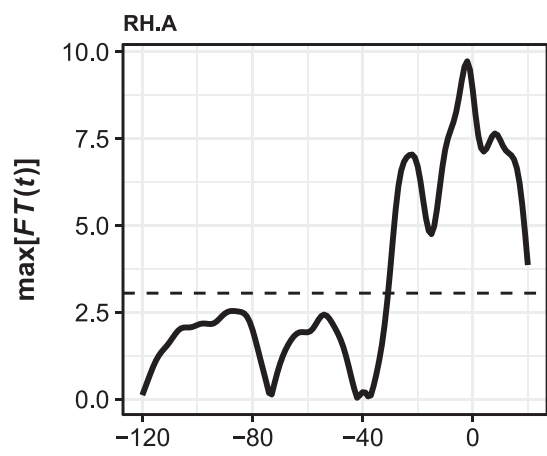

H

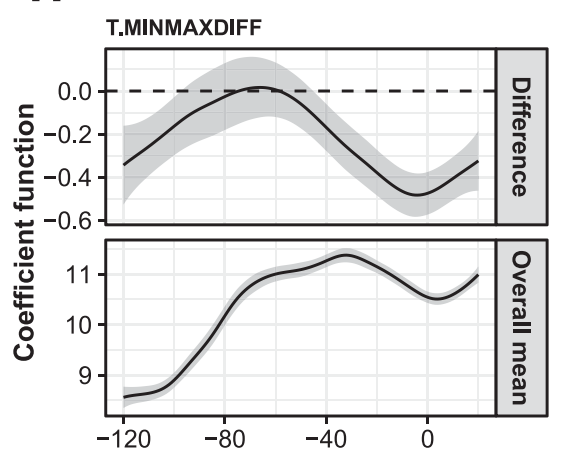

K

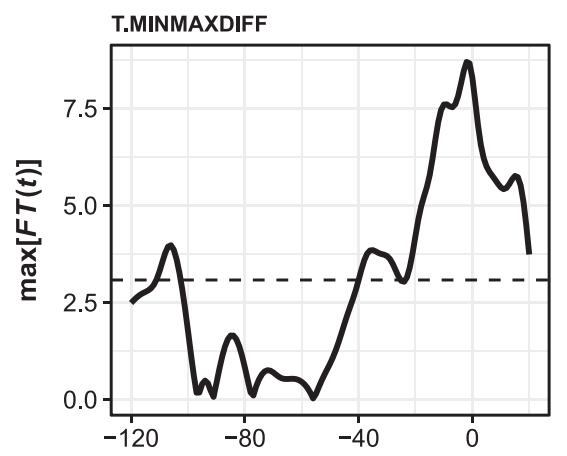

C

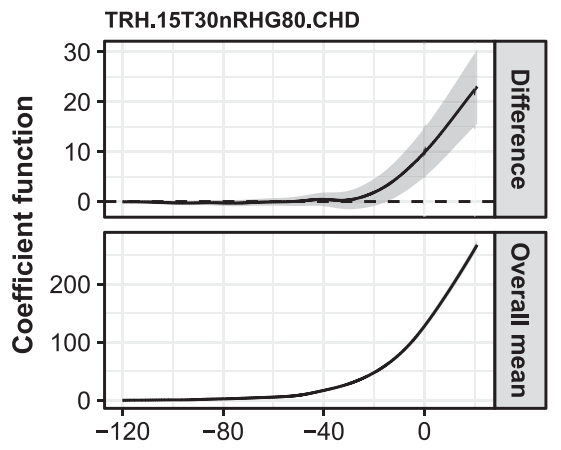

F

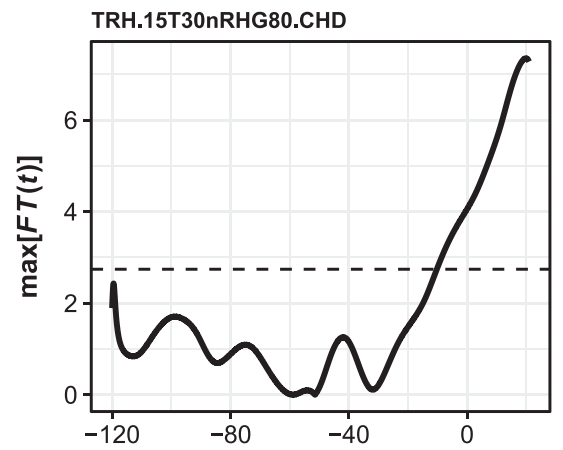

I

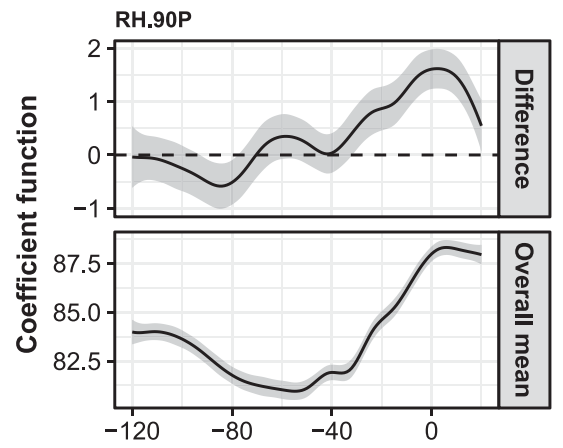

$\mathbf{L}$

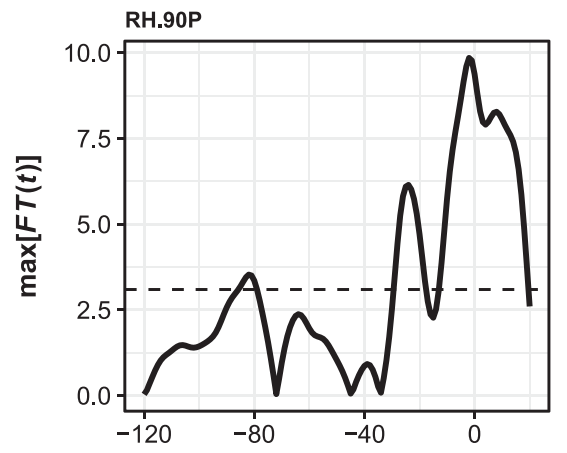

\section{Days relative to anthesis}

Fig. 5. Function-on-scalar regression (equation 4) for six weather variables linked to Fusarium head blight (FHB) observations. A, B, C, G, H, and I, Overall mean $\mu(t)$ and $\beta(t)$, the latter representing the time trend of the mean difference between Fusarium head blight epidemics and nonepidemics. Shaded regions are 95\% pointwise confidence intervals. D, E, $\mathbf{F}, \mathbf{J}, \mathbf{K}$, and $\mathbf{L}$, Test statistic $\max [F T(t)]$ for a functional $t$ test of $\beta(t) \neq 0$. Dashed lines in these latter six panels are the 95 th quantile of the null distribution of $\max [F T(t)]$. Observed values of $\max [F T(t)]$ above the dashed lines indicate regions where $\beta(t) \neq 0$. T.A $=$ daily average temperature $(\mathrm{T}), \mathrm{RH} . \mathrm{A}=$ daily average relative humidity $(\mathrm{RH}), \mathrm{TRH} .15 \mathrm{~T} 30 \mathrm{nRHG} 80 . \mathrm{CHD}=$ cumulative number of hours (starting from 120 days pre-anthesis) in which $15^{\circ} \mathrm{C} \leq \mathrm{T} \leq 30^{\circ} \mathrm{C}$ and $\mathrm{RH} \geq 80 \%$, VPD.L635.CHD = cumulative number of hours (starting from 120 days pre-anthesis) in which vapor pressure deficit $(\mathrm{VPD}) \leq 0.635 \mathrm{kPa}$, T.MINMAXDIFF $=$ the daily difference between the maximum and minimum observed hourly T, and RH.90P $=$ the daily 90 th percentile of observed hourly RH. 
B

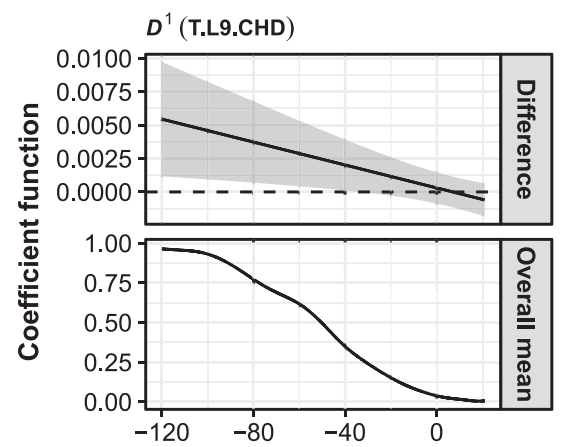

D

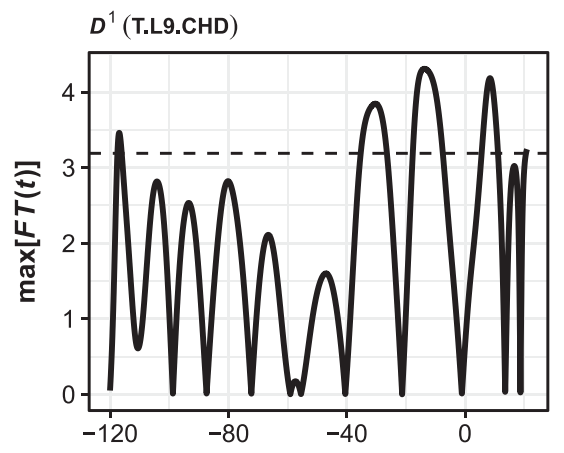

G

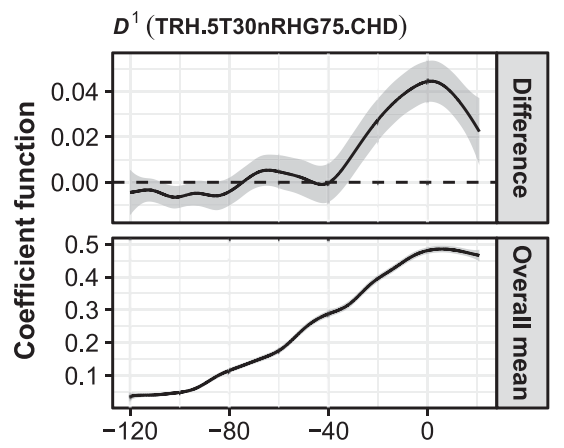

J

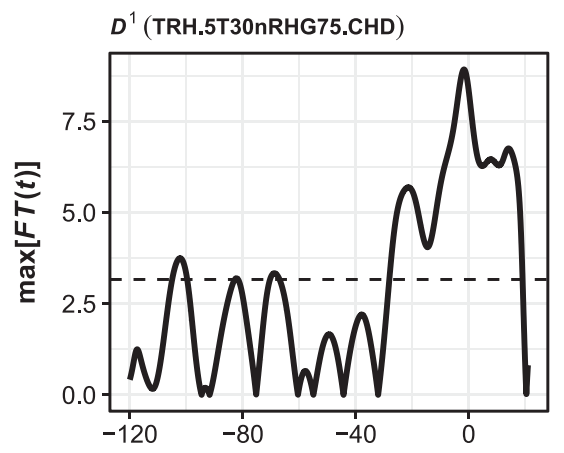

E

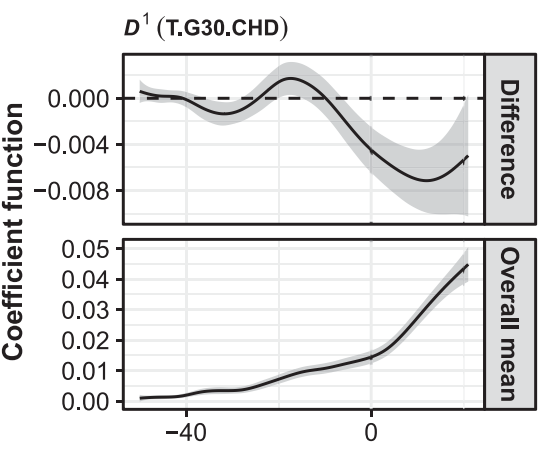

C
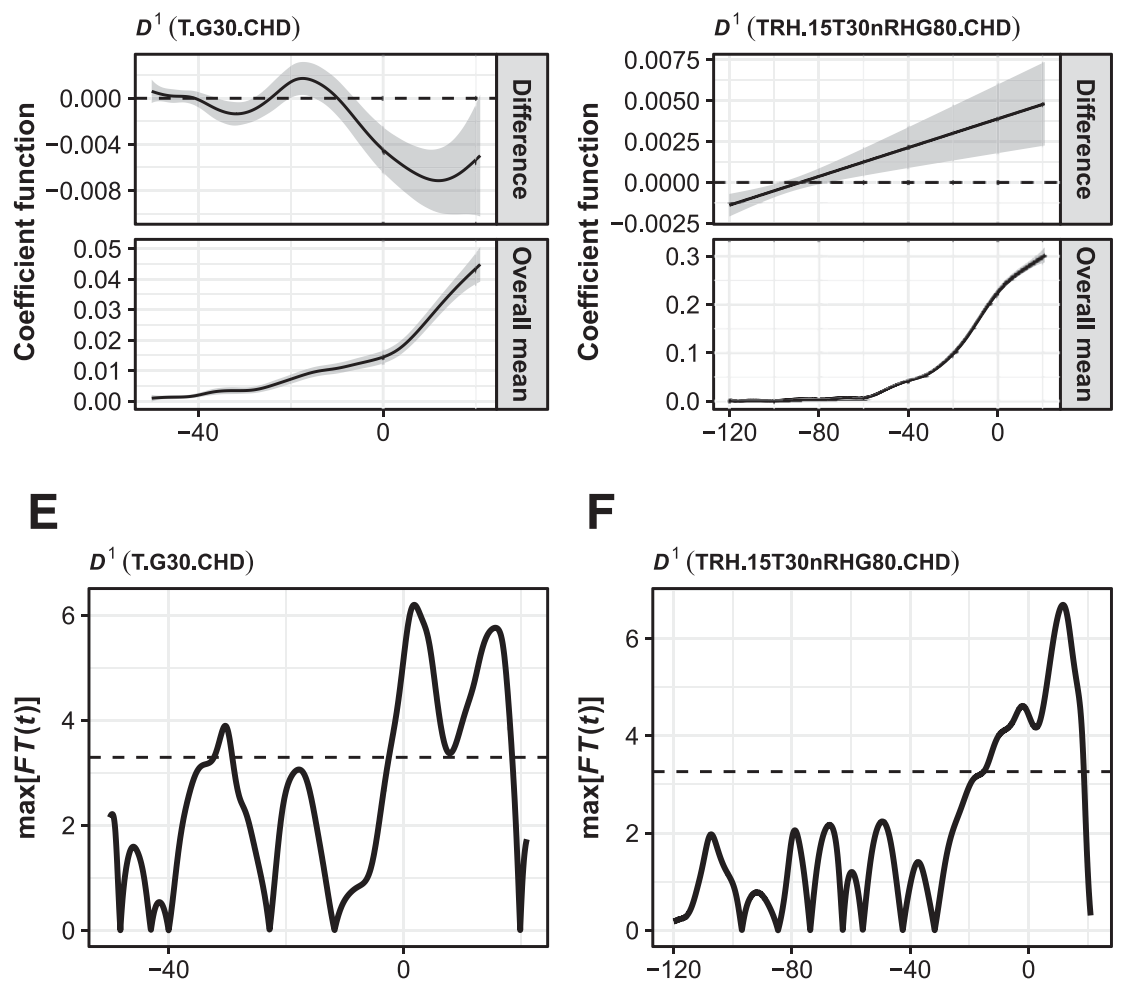

$\mathbf{F}$

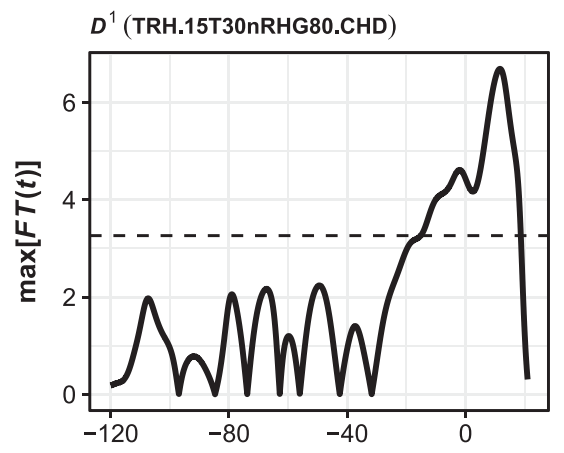

I
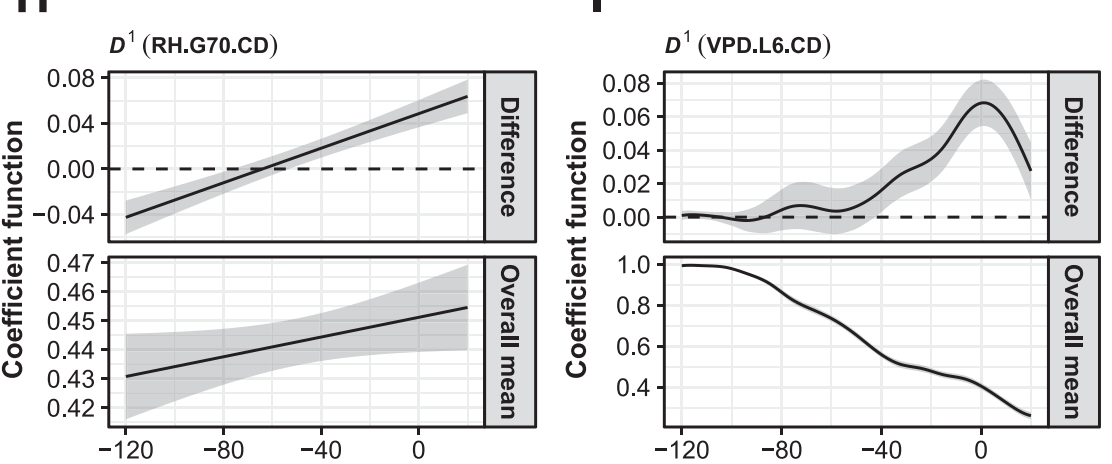

$\mathbf{L}$

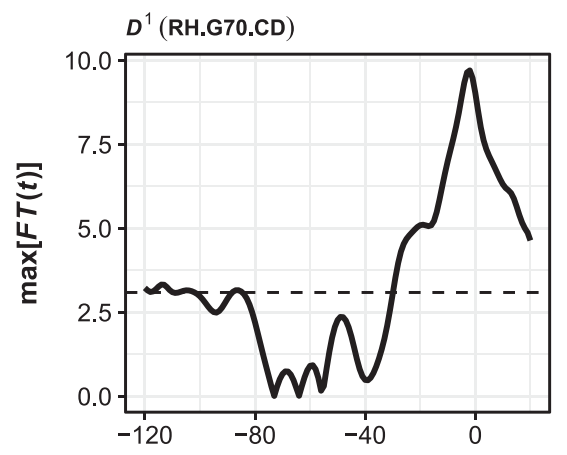

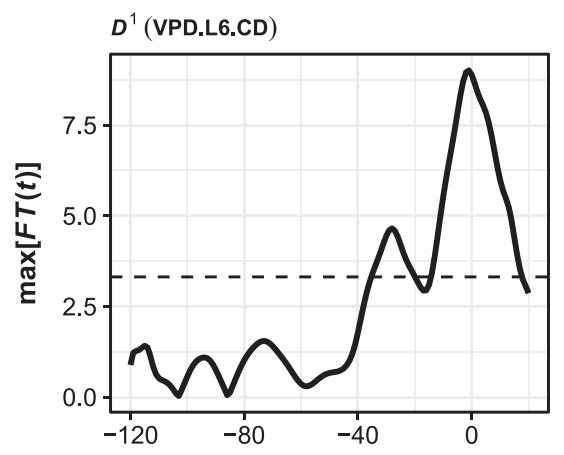

\section{Days relative to anthesis}

Fig. 6. Function-on-scalar regression (equation 4) for the functional first derivatives $\left(D^{1}\right)$ of six weather variables linked to Fusarium head blight (FHB) observations. A, B, C, G, H, and I, Overall mean $\mu(t)$ and $\beta(t)$, the latter representing the time trend of the mean difference between Fusarium head blight epidemics and nonepidemics. Shaded regions are $95 \%$ pointwise confidence intervals. D, E, $\mathbf{F}, \mathbf{J}, \mathbf{K}$, and $\mathbf{L}$, Test statistic max $[F T(t)]$ for a functional $t$ test of $\beta(t) \neq$ 0 . Dashed lines in these latter six panels are the 95th quantile of the null distribution of max $[F T(t)]$. Observed values of max $[F T(t)]$ above the dashed lines indicate regions where $\beta(t) \neq 0$. Each variable represented the cumulative number of hours (ch) or days (cd) in which the specified condition was met, from 120 days preanthesis to 20 days post-anthesis. T.L9.CHD $=$ ch temperature $(\mathrm{T})<9^{\circ} \mathrm{C}, \mathrm{T} . \mathrm{G} 30 . \mathrm{CHD}=\mathrm{ch} \mathrm{T}>30^{\circ} \mathrm{C}, \mathrm{TRH} .15 \mathrm{~T} 30 \mathrm{nRHG} 80 . \mathrm{CHD}=\mathrm{ch} 15^{\circ} \mathrm{C} \leq \mathrm{T} \leq 30^{\circ} \mathrm{C}$ and relative humidity $(\mathrm{RH}) \geq 80 \%$, TRH.5T30nRHG75.CHD $=$ ch $5^{\circ} \mathrm{C} \leq \mathrm{T} \leq 30^{\circ} \mathrm{C}$ and $\mathrm{RH} \geq 75 \%$, RH.G70.CD = cd daily mean RH $>70 \%$, and VPD.L6.CD $=$ cd daily mean vapor pressure deficit $(\mathrm{VPD})<0.6 \mathrm{kPa}$. 
curves (with associated test statistics) for several moisture-related variables. With daily average $\mathrm{RH}$, for instance, the functional mean curve associated with FHB epidemics was higher than the curve associated with nonepidemics beginning approximately 40 days pre-anthesis. The difference between the daily maximum and minimum $\mathrm{RH}$ began trending lower for epidemics as early as 80 days before anthesis. In many cases with moisture-related variables, the differences between the mean functional curves for epidemics and nonepidemics were noticeable as early as 40 days pre-anthesis, and statistically significant from then on through to 20 days post-anthesis.

A 40-day pre-anthesis period incorporates the effects of temperature and moisture-related conditions on $F$. graminearum ascospore production and dissemination (Paul et al. 2007a). Manstretta and Rossi (2016) identified $5^{\circ} \mathrm{C} \leq \mathrm{T} \leq 30^{\circ} \mathrm{C}$ and $\mathrm{RH} \geq$ $75 \%$ as favoring $F$. graminearum perithecia production. We examined one version of this variable (TRH.5T30nRHG75.CHD) in terms of the cumulative number of hours in which the condition was met. The mean rate of accumulation of this condition was higher for FHB epidemics than for nonepidemics from approximately 30 days pre-anthesis onward, with the rate difference peaking at anthesis. We looked at another condition (VPD $\leq 0.635 \mathrm{kPa}$ ), associated with peak discharges of ascospores from $F$. graminearum perithecia (Manstretta and Rossi 2015), recast in two different ways: VPD. L635.CHD and VPD.L6.CD. The latter summarized the accumulation of the condition from a daily means perspective (rather than hourly). The condition specified by VPD.L635.CHD was met more frequently with epidemics than with nonepidemics beginning approximately 40 days pre-anthesis and was statistically higher right at anthesis and through the post-anthesis period. At the daily level, the VPD.L6.CD condition was met less frequently as time progressed (from 120 days pre-anthesis) but it was noteworthy that the rate of accumulation of VPD.L6.CD was consistently higher for epidemics than for nonepidemics beginning approximately 40 days pre-anthesis, with the difference peaking at anthesis. By contrast, the condition specified by T.L9.CHD, reported as being associated with the suppression of perithecia formation (Andries et al. 2000; Dufault et al. 2006), was not consistently linked to either FHB epidemics or nonepidemics in this analysis, even though a version of this variable was selected as a predictor in our FHB logistic regression modeling efforts (Shah et al. 2013). However, that is not to say that T.L9.CHD has no effect on FHB epidemics; equation 4 could be expanded to examine potential associations of T.L9.CHD with FHB epidemics conditional on production region (defined by the prevalence of spring versus winter wheat), cultivar resistance level to FHB, or presence of maize residue (Shah et al. 2013). In winter-wheat-dominant regions, compared with spring-wheatdominant areas, wheat is more likely to be planted into (or next to) prior-season no-tillage maize, potentially increasing exposure of the crop to $F$. graminearum ascospores (Keller et al. 2014). However, low-temperature effects on perithecia formation may be more pronounced in winter wheat, for which the pre-anthesis period occurs earlier in the year and under cooler temperature conditions than in spring wheat.

The largest differences between weather time series associated with FHB epidemics and nonepidemics were found very close to anthesis, corresponding to the period of peak susceptibility of the host to the pathogen (Kazan et al. 2012). The FDA results were congruent with $F$. graminearum being well adapted to host phenology and environmental conditions for maximizing the chance of disease. The fact that conditions associated with epidemics were starting to accumulate from 40 days pre-anthesis onward was not realized through previous fixed-window-length logistic regression and boosted regression tree analyses (Shah et al. 2013, 2014), though there were hints that signals associated with FHB epidemics in weather series could appear much earlier than anthesis, based on the analysis of other data (Kriss et al. 2010). The potential value of these earlier separations between weather variables associated with
FHB epidemics and nonepidemics will be realized if they can be captured in predictive models. The most useful weather variables to target for FHB prediction would be those for which the mean functional curves for epidemics and nonepidemics were consistently well separated over an extended time relative to anthesis. Although there were periods in which the mean curves of T.A.24H could be distinguished, they were narrow, and the difference between the curves flipped direction (from positive to negative). A potentially more useful temperature-related weather variable, with more consistent and extended separation between the mean curves, was T.MINMAXDIFF. From a practical standpoint, FDA will focus the search for FHB predictors within weather variable time series that demonstrated a consistently low or high $\beta(t)$ for more than just a few days at a time.

Despite a stronger connection of FHB epidemics with moisturerelated variables than with T-type variables, it should be noted that, regardless of variable type, differences between the mean functional curves for weather associated with epidemics or nonepidemics were of relatively small magnitude, demonstrated with the standardized differences being mostly below 0.5 in absolute value, regardless of statistical test significance (function-on-scalar modeling). Given the variability among the individual functional curves linked to each FHB observation, our results suggest that predictive weather-based modeling of FHB would benefit from the use of several input variables over potentially different, and possibly overlapping, windows or time frames relative to anthesis.

The current article did not examine functional representations of rainfall, which is a predictor in several FHB forecast models (Franz et al. 2009; Froment et al. 2011; Hooker et al. 2002; Moschini and Fortugno 1996). Rainfall is very site specific (Schleiss and Smith 2016). Even within fields, there can be considerable variation in rain amount and duration (Dzotsi et al. 2014; El Jarroudi et al. 2017). The additional noise introduced because of the weather-datasourcing protocol we used in this article (without interpolation to the actual plot locations) may have made a functional analysis of rain (with respect to FHB epidemics) of low informational value, considering the variability seen with the other weather variables, which are less site-specific by comparison. Nevertheless, a functional analysis of rainfall could be worthwhile if such records are available on site. Fourier or wavelet basis expansions (as opposed to splines) will be of greater value in that respect (El Jarroudi et al. 2017).

An alternative way of addressing the relationship between weather and FHB observations is to ask whether epidemics and nonepidemics could be accurately predicted from the functionally represented weather. This is a scalar-on-function regression problem (the reverse of the function-on-scalar approach here), analogous to logistic regression; except, in the functional setting, each predictor variable is a curve (Aguilera et al. 2008). Scalar-onfunction regression was beyond the scope of the current article but is the focus of current research to improve accuracy of predictions by the national FHB prediction center.

\section{APPENDIX}

Functional representation of time series. The notation in this section parallels that in Kokoszka and Reimherr (2017). Consider a single weather variable $w$ from the set $W$. Each of the $N=865$ FHB observations was linked to a weather time series $w_{n}$, $n=1, \ldots, N$. For any given $w_{n}$, the observed (recorded) data values were of the form $x_{n}\left(t_{j, n}\right)$, with $t_{j, n} \in\left[T_{1}, T_{2}\right], n=1, \ldots, N, j=1, \ldots J_{n}$. Note that $t_{j, n}$ represents the $j^{\text {th }}$ time (e.g., 20 days before anthesis) out of a total of $J_{n}$ observation times for the $n^{\text {th }}$ weather time series. Each $w_{n}$ was observed within the common interval $\left[T_{1}, T_{2}\right]$, and the number of observed points could differ among the $x_{n}$. In the current article, $T_{1}=120$ days pre-anthesis, $T_{2}=20$ days postanthesis, and the $t_{j, n}$ were the same across all $N$ time series for any one of the weather variables. Downloaded weather data covered a 
longer span than the 140 days between $T_{1}$ and $T_{2}$ to allow for imputations should missing data occur near $T_{1}$ or $T_{2}$. The $w_{n}$ were assumed to be smooth, continuous curves within $\left[T_{1}, T_{2}\right]$ but observed only at the points $t_{j, n}$.

In the functional paradigm (Ramsay and Silverman 2005), the interest is in studying the smooth curves

$$
\left\{x_{n}(t): t \in\left[T_{1}, T_{2}\right], n=1, \ldots, N\right\}
$$

where the values $x_{n}(t)$ exist at any $t$ within $\left[T_{1}, T_{2}\right]$ but are only observed at the sampled $t_{j, n}$ (e.g., every minute, hour, or day). Note that $t$ without any subscripts is a continuous (real) value from $T_{1}$ to $T_{2}$; $t$ with subscripts signifies a sampled or specific point within the $\left[T_{1}, T_{2}\right]$ interval at which a weather observation has been recorded. A first step in functional data analysis is the conversion of the observed $x_{n}\left(t_{j, n}\right)$ to a functional form by using a basis expansion:

$$
x_{n}(t) \approx \sum_{m=1}^{M} c_{n m} B_{m}(t), 1 \leq n \leq N
$$

That is, the $x_{n}(t)$ are approximated by a linear expansion of $M$ independent known basis functions $B_{m}$, and, in most cases, $M$ is smaller than the number of observed time points $J_{n}$. Power series, Fourier series, splines, and wavelets are all examples of basis functions (Ramsay and Silverman 2005). If the basis functions are smooth, then equation A2 leads to a smooth representation of the curve $x_{n}$, with the original data $x_{n}\left(t_{j, n}\right)$ having been replaced by the smaller set of the $c_{n m}$ coefficients.

After $x_{n}(t)$ has been approximated via equation $\mathrm{A} 2$, the $i^{\text {th }}$ order derivative function can be obtained by

$$
x_{n}^{(i)}(t) \approx \sum_{m=1}^{M} c_{n m} B_{m}^{(i)}(t)
$$

where the superscript $(i)$ indicates the $i^{\text {th }}$ order derivative (Ramsay and Silverman 2005). For the approximation given by equation A3 to work, it must be $i$ times continuously differentiable and the basis functions used must have at least $i$ finite derivatives.

Therefore, a smoothed representation of $x(t)$ can be obtained (via equation A2) by using a relatively small $M$. However, a drawback with small $M$ is that the fitted curve is restricted in shape, because the smooth functions are linear combinations of the $M$ basis functions (Kokoszka and Reimherr 2017). A solution to this problem is to use many basis functions with some form of penalized smoothing in the curve fitting process (Ruppert et al. 2003).

Penalized smoothing. To simplify the mathematical presentation of the concepts, we now focus on a single weather time series associated with one FHB observation only (with $J$ observations of the weather variable over time; the $n$ subscript is now redundant and is omitted). The observed data values are $y_{j}$ at points $t_{j} \in\left[T_{1}, T_{2}\right]$. Assume there is a smooth curve $x_{j}, t \in\left[T_{1}, T_{2}\right]$ and that $y_{j}=x\left(t_{j}\right)+\varepsilon_{j}$, where $\varepsilon_{j}$ is a random error with an expected value of zero. The assumption that the $y_{j}$ are observed with error is reasonable given that the weather data associated with the FHB observations were not site specific (stations were located some distance from actual plot sites), in addition to any inherent error in data measured by the recording instruments. The goal is obtaining a smooth approximation of $x(t)$ that removes some of the random noise obscuring the underlying temporal trend in the series:

$$
x(t) \approx x_{K}(t)=\sum_{k=1}^{K} c_{k} B_{k}(t)
$$

In this case, $K$ is typically much larger than $M$ in equation $\mathrm{A} 2$, and can even be larger than $J$. In equation $\mathrm{A} 4$, and $x(t)$ will be interpolated exactly when $K=J$ and there is no penalization. However, exact interpolation fails to filter the $\varepsilon_{j}$ out of the series approximation, reduces the degrees of freedom available for hypothesis testing, increases computational effort, and reduces interpretability (Ramsay and Silverman 2005). On the other hand, a $K$ that is too small (also with no penalization; analogous to fitting equation $\mathrm{A} 2$ with a small $M$ ) will smooth away features that may be of importance. A suitable level of smoothing is obtained by penalizing the fit of the curve $x(t)$ to the data $y_{j}$, thereby balancing between too much smoothing and overfitting (i.e., too much wiggliness in the fitted curve).

To set up the penalization machinery, first define a linear differential operator $L(x)$ which is a linear combination of $m$ derivatives of $x$ :

$$
L(x)(t)=\alpha_{0}(t) x(t)+\alpha_{1}(t) x^{(1)}(t)+\ldots+\alpha_{\mathrm{m}}(t) x^{m}(t)
$$

where $x^{m}$ is the $m^{\text {th }}$ derivative of $x$ and the $\alpha$ are coefficients. Depending on the application, the number of derivatives may be limited to one or two, thus simplifying equation A5. The smoothed representation is then obtained with the penalized sum of squares,

$$
\operatorname{PSS}_{\lambda}\left(c_{1}, c_{2}, \ldots, c_{K}\right)=\sum_{j}\left(y_{j}-x_{K}\left(t_{j}\right)\right)^{2}+\lambda \int_{T_{1}}^{T_{2}}\left[L\left(x_{K}\right)(t)\right]^{2} d t
$$

where $\lambda$ is a parameter chosen by the investigator (arbitrarily) or by using one of several algorithms. If $\lambda=0$ in equation $A 6$, then there is no penalization, and the basis expansion for $x(t)$ is the same as given in equation A2. As $\lambda$ becomes larger, the penalty term in equation A6 exerts more influence on $\mathrm{PSS}_{\lambda}$, resulting in less wiggliness in the fitted curve. The penalized least-squares solution of the coefficients $c_{k}$ are then used in equation A4 to obtain the fitted functional representation of $x(t)$.

For the weather time series, cubic B-splines (Eubank 1999) were used for the basis functions $B_{k}(t)$ (equation A4). B-splines are a common choice for nonperiodic functional data (Gertheiss et al. 2015; Masselot et al. 2016). Cubic splines facilitate smooth (continuous) first-derivative functions, which allowed for exploration of the rates of change in weather variables with respect to FHB epidemics. The second-derivative linear differential operator $L(x)$ $(t)=x^{(2)}(t)$ was used in the penalization term (equation A6; $\alpha_{2}(t)=1$, all other terms set to zero). The parameters $K$ and $\lambda$ can be chosen via generalized cross-validation (GCV) (Ramsay and Silverman 2005) or mixed-model fitting (Madden and Paul 2010; Ruppert et al. 2003), or determined by subject domain knowledge. Choices for $K$ and $\lambda$ were explored via GCV and visual inspection of the smoothed functions for several combinations of $K$ and $\lambda$, leading to a selection of $K=19$ and $\lambda=50$ for the functional representations of the weather time series. Although penalized smoothing was presented above in terms of a single series (equations A4, A5, and A6), note that, in practice, estimation of the $c_{n, k}$ coefficients was done with the same $K$ and $\lambda$ applied to all $N$ series of a given weather variable.

\section{ACKNOWLEDGMENTS}

We thank the many collaborators who have contributed data over the years, without whom this research would not have been possible. Any opinions, findings, conclusions, or recommendations expressed in this publication are those of the authors and do not necessarily reflect the view of the United States Department of Agriculture.

\section{LITERATURE CITED}

Aguilera, A. M., Escabias, M., and Valderrama, M. J. 2008. Discussion of different logistic models with functional data. Application to systemic lupus erythematosus. Comput. Stat. Data Anal. 53:151-163.

Andries, C., Jarosz, A., and Trail, F. 2000. Effects of rainfall and temperature on production of perithecia by Gibberella zeae in field debris in Michigan. Pages 118-119 in: 2000 Natl. Fusarium Head Blight Forum, Erlanger, KY.

Bianchini, A., Horsley, R., Jack, M. M., Kobielush, B., Ryu, D., Tittlemier, S., Wilson, W. W., Abbas, H. K., Abel, S., Harrison, G., Miller, J. D., Shier, 
W. T., and Weaver, G. 2015. DON occurrence in grains: A North American perspective. Cereal Foods World 60:32-56.

Bonner, S. J., Newlands, N. K., and Heckman, N. E. 2014. Modeling regional impacts of climate teleconnections using functional data analysis. Environ. Ecol. Stat. 21:1-26.

Coakley, S. M., McDaniel, L. R., and Line, R. F. 1988. Quantifying how climatic factors affect variation in plant disease severity: A general method using a new way to analyze meteorological data. Clim. Change 12:57-75.

Cowger, C., and Arrellano, C. 2010. Plump kernels with high deoxynivalenol linked to late Gibberella zeae infection and marginal disease conditions in winter wheat. Phytopathology 100:719-728.

Cowger, C., Weisz, R., Arellano, C., and Murphy, P. 2016. Profitability of integrated management of Fusarium head blight in North Carolina winter wheat. Phytopathology 106:814-823.

D’Angelo, D. L., Bradley, C. A., Ames, K. A., Willyerd, K. T., Madden, L. V., and Paul, P. A. 2014. Efficacy of fungicide applications during and after anthesis against Fusarium head blight and deoxynivalenol in soft red winter wheat. Plant Dis. 98:1387-1397.

Del Ponte, E. M., Fernandes, J. M. C., and Bergstrom, G. C. 2007. Influence of growth stage on fusarium head blight and deoxynivalenol production in wheat. J. Phytopathol. 155:577-581.

De Wolf, E. D., Madden, L. V., and Lipps, P. E. 2003. Risk assessment models for wheat Fusarium head blight epidemics based on within-season weather data. Phytopathology 93:428-435.

Dufault, N. S., De Wolf, E. D., Lipps, P. E., and Madden, L. V. 2006. Role of temperature and moisture in the production and maturation of Gibberella zeae perithecia. Plant Dis. 90:637-644.

Dzotsi, K. A., Matyas, C. J., Jones, J. W., Baigorria, G., and Hoogenboom, G. 2014. Understanding high resolution space-time variability of rainfall in southwest Georgia, United States. Int. J. Climatol. 34:3188-3203.

El Jarroudi, M., Kouadio, L., El Jarroudi, M., Junk, J., Bock, C., Diouf, A. A., and Delfosse, P. 2017. Improving fungal disease forecasts in winter wheat: A critical role of intra-day variations of meteorological conditions in the development of Septoria leaf blotch. Field Crops Res. 213:12-20.

Eubank, R. L. 1999. Spline Smoothing and Nonparametric Regression, 2nd ed. Marcel Dekker, New York.

Ferrigo, D., Raiola, A., and Causin, R. 2016. Fusarium toxins in cereals: Occurrence, legislation, factors promoting the appearance and their management. Molecules 21:627.

Franz, E., Booij, K., and van der Fels-Klerx, I. 2009. Prediction of deoxynivalenol content in Dutch winter wheat. J. Food Prot. 72:2170-2177.

Freije, A. N., and Wise, K. A. 2015. Impact of Fusarium graminearum inoculum availability and fungicide application timing on Fusarium head blight in wheat. Crop Prot. 77:139-147.

Froment, A., Gautier, P., Nussbaumer, A., and Griffiths, A. 2011. Forecast of mycotoxins levels in soft wheat, durum wheat and maize before harvesting with Qualimètre ${ }^{\circledR}$. J. Verbrauch. Lebensm. 6:277-281.

Gent, D. H., Mahaffee, W. F., McRoberts, N., and Pfender, W. F. 2013. The use and role of predictive systems in disease management. Annu. Rev. Phytopathol. 51:267-289.

Gertheiss, J., Maier, V., Hessel, E., and Staicu, A.-M. 2015. Marginal functional regression models for analyzing the feeding behavior of pigs. J. Agric. Biol. Environ. Stat. 20:353-370.

Gilbert, J., and Haber, S. 2013. Overview of some recent research developments in Fusarium head blight of wheat. Can. J. Plant Pathol. 35: $149-174$

Giroux, M. E., Bourgeois, G., Dion, Y., Rioux, S., Pageau, D., Zoghlami, S., Parent, C., Vachon, E., and Vanasse, A. 2016. Evaluation of forecasting models for Fusarium head blight of wheat under growing conditions of Quebec, Canada. Plant Dis. 100:1192-1201.

Gouache, D., Leon, M. S., Duyme, F., and Braun, P. 2015. A novel solution to the variable selection problem in Window Pane approaches of plant pathogenClimate models: Development, evaluation and application of a climatological model for brown rust of wheat. Agric. For. Meteorol. 205:51-59.

Greven, S., and Scheipl, F. 2017. A general framework for functional regression modelling. Stat. Model. 17:1-35.

Hollingsworth, C. R., Mewes, J. J., Motteberg, C. D., and Thompson, W. G. 2006. Predictive accuracy of a Fusarium head blight epidemic risk forecasting system deployed in Minnesota. Online publication. Plant Health Prog. doi:10.1094/PHP-2006-1031-01-RS

Hooker, D. C., Schaafsma, A. W., and Tamburic-Ilincic, L. 2002. Using weather variables pre- and post-heading to predict deoxynivalenol content in winter wheat. Plant Dis. 86:611-619.

Jin, F., Zhang, D. D., Bockus, W., Baenziger, P. S., Carver, B., and Bai, G. H. 2013. Fusarium head blight resistance in U.S. winter wheat cultivars and elite breeding lines. Crop Sci. 53:2006-2013.

Junger, W. L., Ponce de Leon, A., and Santos, N. 2003. Missing data imputation in multivariate time series via EM algorithm. Cadernos IME 15:8-21.
Kazan, K., Gardiner, D. M., and Manners, J. M. 2012. On the trail of a cereal killer: Recent advances in Fusarium graminearum pathogenomics and host resistance. Mol. Plant Pathol. 13:399-413.

Keller, M. D., Bergstrom, G. C., and Shields, E. J. 2014. The aerobiology of Fusarium graminearum. Aerobiologia 30:123-136.

Kokoszka, P., and Reimherr, M. 2017. Introduction to Functional Data Analysis. CRC Press, Boca Raton, FL.

Kriss, A. B., Paul, P. A., and Madden, L. V. 2010. Relationship between yearly fluctuations in Fusarium head blight intensity and environmental variables: A window-pane analysis. Phytopathology 100:784-797.

Landschoot, S., Waegeman, W., Audenaert, K., Haesaert, G., and De Baets, B. 2013a. Ordinal regression models for predicting deoxynivalenol in winter wheat. Plant Pathol. 62:1319-1329.

Landschoot, S., Waegeman, W., Audenaert, K., Van Damme, P., Vandepitte, J., De Baets, B., and Haesaert, G. 2013b. A field-specific web tool for the prediction of Fusarium head blight and deoxynivalenol content in Belgium. Comput. Electron. Agric. 93:140-148.

Landschoot, S., Waegeman, W., Audenaert, K., Vandepitte, J., Baetens, J. M., De Baets, B., and Haesaert, G. 2012. An empirical analysis of explanatory variables affecting Fusarium head blight infection and deoxynivalenol content in wheat. J. Plant Pathol. 94:135-147.

Leplat, J., Friberg, H., Abid, M., and Steinberg, C. 2013. Survival of Fusarium graminearum, the causal agent of Fusarium head blight. A review. Agron. Sustain. Dev. 33:97-111.

Madden, L. V., and Paul, P. A. 2010. An assessment of mixed-modeling approaches for characterizing profiles of time-varying response and predictor variables. Phytopathology 100:1015-1029.

Manstretta, V., and Rossi, V. 2015. Effects of weather variables on ascospore discharge from Fusarium graminearum perithecia. PLOS One 10:e138860.

Manstretta, V., and Rossi, V. 2016. Effects of temperature and moisture on development of Fusarium graminearum perithecia in maize stalk residues. Appl. Environ. Microbiol. 82:184-191.

Masselot, P., Dabo-Niang, S., Chebana, F., and Ouarda, T. B. M. J. 2016. Streamflow forecasting using functional regression. J. Hydrol. (Amst.) 538: 754-766.

Molineros, J. E. 2007. Understanding the challenges of Fusarium head blight forecasting. Dissertation, The Pennsylvania State University, University Park

Monteith, J. L., and Unsworth, M. H. 2008. Principles of Environmental Physics, 3rd ed. Academic Press, Burlington, MA.

Morris, J. S. 2015. Functional regression. Annu. Rev. Stat. Appl. 2:321-359.

Moschini, R. C., and Fortugno, C. 1996. Predicting wheat head blight incidence using models based on meteorological factors in Pergamino, Argentina. Eur. J. Plant Pathol. 102:211-218.

Nganje, W. E., Bangsund, D. A., Leistritz, F. L., Wilson, W. W., and Tiapo, N. M. 2004. Regional economic impacts of Fusarium head blight in wheat and barley. Rev. Agric. Econ. 26:332-347.

O’Donnell, K., Kistler, H. C., Tacke, B. K., and Casper, H. H. 2000. Gene genealogies reveal global phylogeographic structure and reproductive isolation among lineages of Fusarium graminearum, the fungus causing wheat scab. Proc. Natl. Acad. Sci. USA 97:7905-7910.

O’Donnell, K., Ward, T. J., Geiser, D. M., Kistler, H. C., and Aoki, T. 2004. Genealogical concordance between the mating type locus and seven other nuclear genes supports formal recognition of nine phylogenetically distinct species within the Fusarium graminearum clade. Fungal Genet. Biol. 41:600-623.

Osborne, L. E., and Stein, J. M. 2007. Epidemiology of Fusarium head blight on small-grain cereals. Int. J. Food Microbiol. 119:103-108.

Paul, P. A., Lipps, P. E., De Wolf, E., Shaner, G., Buechley, G., Adhikari, T., Ali, S., Stein, J., Osborne, L., and Madden, L. V. 2007a. A distributed lag analysis of the relationship between Gibberella zeae inoculum density on wheat spikes and weather variables. Phytopathology 97:1608-1624.

Paul, P. A., Lipps, P. E., Hershman, D. E., McMullen, M. P., Draper, M. A., and Madden, L. V. 2007b. A quantitative review of tebuconazole effect on Fusarium head blight and deoxynivalenol content in wheat. Phytopathology 97:211-220.

Paul, P. A., Lipps, P. E., Hershman, D. E., McMullen, M. P., Draper, M. A., and Madden, L. V. 2008. Efficacy of triazole-based fungicides for Fusarium head blight and deoxynivalenol control in wheat: A multivariate metaanalysis. Phytopathology 98:999-1011.

Paul, P. A., Lipps, P. E., and Madden, L. V. 2005. Relationship between visual estimates of Fusarium head blight intensity and deoxynivalenol accumulation in harvested wheat grain: A meta-analysis. Phytopathology 95: 1225-1236.

Paul, P. A., McMullen, M. P., Hershman, D. E., and Madden, L. V. 2010. Metaanalysis of the effects of triazole-based fungicides on wheat yield and test weight as influenced by Fusarium head blight intensity. Phytopathology 100:160-171.

Pietravalle, S., Shaw, M. W., Parker, S. R., and van den Bosch, F. 2003. Modeling of relationships between weather and Septoria tritici epidemics on winter wheat: A critical approach. Phytopathology 93:1329-1339. 
Prat, N., Buerstmayr, M., Steiner, B., Robert, O., and Buerstmayr, H. 2014. Current knowledge on resistance to Fusarium head blight in tetraploid wheat. Mol. Breed. 34:1689-1699.

Ramsay, J. O., Hooker, G., and Graves, S. 2009. Functional Data Analysis with $\mathrm{R}$ and MATLAB. Springer, New York.

Ramsay, J. O., and Silverman, B. W. 2005. Functional Data Analysis, 2nd ed. Springer, New York.

Ruppert, D., Wand, M. P., and Carroll, R. J. 2003. Semiparametric Regression. Cambridge University Press, Cambridge, UK.

Salgado, J. D., Madden, L. V., and Paul, P. A. 2014. Efficacy and economics of integrating in-field and harvesting strategies to manage Fusarium head blight of wheat. Plant Dis. 98:1407-1421.

Salgado, J. D., Wallhead, M., Madden, L. V., and Paul, P. A. 2011. Grain harvesting strategies to minimize grain quality losses due to Fusarium head blight in wheat. Plant Dis. 95:1448-1457.

Schaafsma, A. W., and Hooker, D. C. 2007. Climatic models to predict occurrence of Fusarium toxins in wheat and maize. Int. J. Food Microbiol. 119:116-125.

Schleiss, M., and Smith, J. A. 2016. Two simple metrics for quantifying rainfall intermittency: The burstiness and memory of interamount times. J. Hydrometeorol. 17:421-436.

Shah, D. A., De Wolf, E. D., Paul, P. A., and Madden, L. V. 2014. Predicting Fusarium head blight epidemics with boosted regression trees. Phytopathology 104:702-714.

Shah, D. A., Molineros, J. E., Paul, P. A., Willyerd, K. T., Madden, L. V., and De Wolf, E. D. 2013. Predicting Fusarium head blight epidemics with weather-driven pre- and post-anthesis logistic regression models. Phytopathology 103:906-919.

Sørensen, H., Goldsmith, J., and Sangalli, L. M. 2013. An introduction with medical applications to functional data analysis. Stat. Med. 32:5222-5240.

Starkey, D. E., Ward, T. J., Aoki, T., Gale, L. R., Kistler, H. C., Geiser, D. M., Suga, H., Toth, B., Varga, J., and O'Donnell, K. 2007. Global molecular surveillance reveals novel Fusarium head blight species and trichothecene toxin diversity. Fungal Genet. Biol. 44:1191-1204.

Te Beest, D. E., Paveley, N. D., Shaw, M. W., and van den Bosch, F. 2008. Disease-weather relationships for powdery mildew and yellow rust on winter wheat. Phytopathology 98:609-617. te Beest, D. E., Shaw, M. W., Pietravalle, S., and van den Bosch, F. 2009. A predictive model for early-warning of Septoria leaf blotch on winter wheat. Eur. J. Plant Pathol. 124:413-425.

Trail, F. 2009. For blighted waves of grain: Fusarium graminearum in the postgenomics era. Plant Physiol. 149:103-110.

Walter, S., Nicholson, P., and Doohan, F. M. 2010. Action and reaction of host and pathogen during Fusarium head blight disease. New Phytol. 185: 54-66.

Wang, J. L., Chiou, J. M., and Muller, H. G. 2016. Functional data analysis. Annu. Rev. Stat. Appl. 3:257-295.

Wegulo, S. N. 2012. Factors influencing deoxynivalenol accumulation in small grain cereals. Toxins (Basel) 4:1157-1180.

Wegulo, S. N., Baenziger, P. S., Nopsa, J. H., Bockus, W. W., and Hallen-Adams, H. 2015. Management of Fusarium head blight of wheat and barley. Crop Prot. 73:100-107.

Wegulo, S. N., Bockus, W. W., Nopsa, J. H., De Wolf, E. D., Eskridge, K. M., Peiris, K. H. S., and Dowell, F. E. 2011. Effects of integrating cultivar resistance and fungicide application on Fusarium head blight and deoxynivalenol in winter wheat. Plant Dis. 95:554-560.

Willyerd, K. T., Li, C., Madden, L. V., Bradley, C. A., Bergstrom, G. C., Sweets, L. E., McMullen, M., Ransom, J. K., Grybauskas, A., Osborne, L., Wegulo, S. N., Hershman, D. E., Wise, K., Bockus, W. W., Groth, D., Dill-Macky, R., Milus, E., Esker, P. D., Waxman, K. D., Adee, E. A., Ebelhar, S. E., Young, B. G., and Paul, P. A. 2012. Efficacy and stability of integrating fungicide and cultivar resistance to manage Fusarium head blight and deoxynivalenol in wheat. Plant Dis. 96:957-967.

Xu, X., Madden, L. V., and Edwards, S. G. 2014. Modelling the effects of environmental conditions on HT2 andT2 toxin accumulation in field oat grains. Phytopathology 104:57-66.

Xu, X., Madden, L. V., Edwards, S. G., Doohan, F. M., Moretti, A., Hornok, L., Nicholson, P., and Ritieni, A. 2013. Developing logistic models to relate the accumulation of DON associated with Fusarium head blight to climatic conditions in Europe. Eur. J. Plant Pathol. 137: 689-706.

Yuen, J., and Mila, A. 2015. Landscape-scale disease risk quantification and prediction. Annu. Rev. Phytopathol. 53:471-484. 